\section{EJERCICIOS DE DISCRIMINACIÓN Y TECNOLOGÍAS DE PODER: EL CRIMEN DE ESTADO COMO CATEGORÍA PARA EL DERECHO EN EL NUEVO HUMANISMO MILITAR*}

\author{
EXERCISES OF DISCRIMINATION AND \\ TECHNOLOGIES OF POWER: THE STATE \\ CRIMINALITY AS A CATEGORY OF LAW IN \\ THE NEW MILITARY HUMANISM
} EXERCÍCIOS DE DISCRIMINAÇÃO E
TECNOLOGIAS DO PODER: O CRIME DE ESTADO
COMO UMA CATEGORIA PARA O DIREITO NO
NOVO HUMANISMO MILITAR

\section{Sandra Gamboa Rubiano ${ }^{a}$} darziag@gmail.com

Fecha de recepción: 30 de enero 2015 Fecha de revisión: 2 de febrero 2015 Fecha de aceptación: 15 de febrero 2015

\title{
RESUMEN
}

El texto discute la actualidad de la criminalidad de Estado como concepto para el Derecho, y en particular como biopolítica y aspecto del Estado moderno que se profundiza en el contexto del Nuevo Humanismo Militar, y se ejerce como una tecnología de poder que implica ejercicios de discriminación a través de procesos de selección.

\section{PALABRAS CLAVE}

Discriminación, Estado moderno, Corte Penal Internacional, Nuevo Humanismo Militar, Selección, Crímenes de Estado.

\footnotetext{
*Artículo de reflexión resultado de investigación. Documento elaborado como disertación para la tesis doctoral "Solicitudes de las víctimas de crímenes de Estado ante la Corte Penal Internacional: su incidencia en la apertura de una investigación", en el marco del Doctorado en Derecho de la Universidad Santo Tomás.

a. Abogada de la Universidad Nacional de Colombia. Doctora en Derecho, y Magíster en Defensa de los Derechos Humanos ante organismos tribunales y cortes internacionales de la Universidad Santo Tomás. Docente Universitaria y Defensora de los Derechos Humanos.
}

\footnotetext{
MISIÓN JURÍDICA Revista de Derecho y Ciencias Sociales Bogotá, D.C. (Colombia) Colaboradores Externos Internacionales Núm. 8, Año 2015 enero-junio, pp. 87-111.
ISSN 1794-600X
} 


\begin{abstract}
The text discusses the current State criminality as a concept of law studies. Particularly in the biopolitics and in the modern State theories, subscribed in the context of the New Military Humanism. It takes place as a technology of power that involves discrimination exercises through a selection process.
\end{abstract}

\section{KEY WORDS}

Discrimination, Modern State, International Criminal Court, NewMilitary Humanism, Selection, State Crime.

\section{RESUMO}

0 texto discute o crime de Estado como um conceito do Direito e, em particular, como biopolítica e aspecto do Estado moderno, que se aprofunda no contexto do Novo Humanismo Militar, e se exerce como uma tecnologia de poder que envolve exercícios de discriminação através de processos de seleção.

\section{PALAVRAS-CHAVE}

Discriminação, Estado moderno, Tribunal Penal Internacional, Novo Humanismo Militar, crimes de Estado.

\section{INTRODUCCIÓN}

Este artículo es un desafío contra la afirmación más apreciada y esencial de la historia oficial: que el triunfo del capitalismo nace de la libertad, que el libre mercado desregulado va de la mano de la democracia. En lugar de eso, demostraré que esta forma fundamentalista del capitalismo ha surgido en un brutal parto cuyas comadronas han sido la violencia y la coerción, inflingidas en el cuerpo político colectivo así como en innumerables cuerpos individuales. La historia del libre mercado contemporáneo - el auge del corporativismo, en realidad- ha sido escrita con letras de shock (Klein, 2007, p. 43).

Michel Foucault (1996a) encuentra que el poder se organiza de manera interrelacionada y no excluyente, ya como disciplina cuando se tiene por objeto el cuerpo individual, o como Biopolítica si el objeto es el cuerpo social. Esta es una de las más interesantes reflexiones en su pensamiento que se suma a las transformaciones que generó por sus específicas consideraciones sobre el poder, y la metodología para abordarlo. Señala que el poder se ejerce y circula, pero no se reparte de manera universal entre las personas, sino que dicha distribución es ya democrática como anárquica, por lo que postula un análisis antecedente del poder:

(...) partir de los mecanismos infinitesimales (que tienen su historia, su trayecto, su técnica y su táctica) y después ver cómo estos mecanismos de poder que tienen su solidez y su tecnología específica) han sido y son aún investidos, colonizados, utilizados, doblegados, transformados, trasladados, extendidos por mecanismos cada vez más generales y por formas de dominación global (p. 32).

La característica central del poder moderno es que el Estado se construyó al tiempo como individualizante y totalitario (Foucault, 1998). No podría ser diferente cuando se recuerda que la tecnología de poder se centra en la vida y se consolida históricamente en una sociedad normalizadora (Foucault, 1998), como la que tuvo lugar a partir de la segunda mitad del siglo XIX. Una sociedad biopolítica, no disciplinaria. Esto quiere decir que se ubica en otro nivel al de la técnica disciplinaria, y que se traslada del cuerpo a la vida de los seres humanos. Una biopolítica que trabaja con la población como problema biológico y del poder (Foucault, 1998).

En Foucault (1990), las tecnologías de poder junto a las tecnologías de producción, de sistemas de signos y las tecnologías del yo, constituyen una matriz de la razón práctica y sustentan los juegos de verdad que se enmascaran como ciencias. Estos juegos (la economía, la biología, la psiquiatría, la medicina y la penología) son las maneras en que bajo la cultura actual, los seres humanos desarrollan un saber sobre sí mismos. Una tecnología de poder constituye una táctica en acción (Foucault, 1998), una técnica que determina la conducta de los individuos, "los someten a cierto tipo de fines o de dominación, y consisten en una objetivación del sujeto" (Foucault, 1990, p. 48). En particular, la tecnología de poder es "un tipo de poder, una modalidad para ejercerlo" (Foucault, 2012b). Con fundamento en esta postura, Feierstein (2008) ha señalado que el genocidio de Estado constituye "una 
tecnología de poder peculiar, con causas, efectos y consecuencias específicos, que pueden intentar ser rastreados y analizados" (p. 13). Por ello, la existencia de víctimas de crímenes de Estado resalta la visión del Derecho como instrumento de dominación, y revela la puesta en práctica de una tecnología del poder consistente en la objetivización del sujeto. Por esta misma razón, el Crimen de Estado se inscribe en la modernidad, y en particular en la razón instrumental, pero no es privativo de occidente.

Definir la criminalidad de Estado como tecnología de poder, implica asumirla más profundamente que como latencia de la modernidad (Feierstein, 2008). Pero adicionalmente, la fusión de la biopolítica con los rasgos de la modernidad es cuando menos inquietante. Solo deberá advertirse que esta última se traduce en un estado de amenaza y devenir permanente, donde la modernidad capitalista se implementó de la mano de la racionalidad instrumental como instrumento de deshumanización que se mantiene. Tan categórica afirmación que se sintetiza en el Crimen de Estado como holocausto, exige revisar las vinculaciones entre Estado, Derecho y crimen de Estado. En otros trabajos se ha explicitado que el crimen de Estado no es una situación insular, y se ha comprendido que la maldad individual es un mito implementado para desconocer la existencia y asegurar la eficacia del crimen de Estado. A continuación se revisará la criminalidad de Estado como concepto de la modernidad, esto es, bajo una dimensión sociológica de su existencia.

\section{METODOLOGÍA}

Este texto es un artículo de reflexión resultado de investigación, se trata de un estudio teórico que revisa los elementos que identifican el crimen de Estado, a fin de reconocerlo o desestimarlo bajo la grilla de discusión del Nuevo Humanismo Militar, como momento de la modernidad actual que tiene lugar a partir del 11 de septiembre de 2001. A través del método analítico se contrasta la teoría foucoltiana de la biopolítica y la concepción de genocidio como práctica social de Daniel Feierstein, para aclarar bajo el marco teórico del pensamiento crítico, si el crimen de Estado constituye expresión de estos dos fenómenos. En la medida en que se propone la discusión sobre una categoría sociojurídica como el crimen de Estado en el Nuevo Humanismo Militar, se utiliza una estrategia de investigación exploratoria, $\mathrm{y}$ en tanto se tienden puentes entre análisis diferenciados como la Biopolítica y el Nuevo Humanismo Militar, aun cuando inscritos en el pensamiento crítico; también se da uso a una metodología descriptiva.

\section{EL CRIMEN DE ESTADO: EL HOLOCAUSTO COMO TECNOLOGÍA DE PODER}

Bajo múltiples tradiciones es posible admitir que el crimen de Estado es uno de sus rasgos del proceso de la modernidad y del devenir que la signan. También puede considerarse como establecida la incidencia de la concepción de la soberanía en la dimensión de la criminalidad de Estado, y en la posibilidad de su procesamiento por el Derecho Penal nacional (nivel interno), como por el DPI (nivel externo del Estado). Es momento pues, de explicitar estos hallazgos.

A partir de la discusión de la soberanía y sus límites, bajo Bodin (1997), de manera inmediata no cabría el crimen de Estado como concepto, aún cuando remotamente pudiese hacerse derivar de la transgresión del Derecho natural, al que estaría obligado el soberano. Pero sostenerlo no resuelve el problema relativo a la inexistencia de un tribunal humano que pudiese tramitar la facticidad y sanción de esta ofensa, bajo las condiciones de poder absoluto, perpetuo e ilimitado del soberano bajo la postura de Bodin.

Desde Rousseau (1989) se haría más realista la idea de criminalidad de Estado, como se genera a partir de la condensación de varios de sus postulados: (i) En cuanto el crimen de Estado traspasa los límites del contrato social; (ii) como fenómeno que colisiona con la libertad, lo que implica una renuncia a la propia humanidad; (iii) en virtud de la determinación de que el derecho del más fuerte no constituye derecho, pues se mantendría "la obligación de obedecer a los poderes legítimos" (p. 11), (iv) reconociendo que el soberano no puede tener interés contrario a los particulares, pues estos le conforman. Si además se atiende que para Rousseau (1989) el ser humano no puede enajenarse a sí mismo, pues ello implicaría renuncia a los derechos y deberes de la humanidad; podría advertirse que a partir del contractualismo, la transgresión de esta libertad es un crimen: "También hay tranquilidad en los calabozos; ¿basta esto para hacerlos agradables?” 
(p. 12). No obstante, su idea de crimen de Estado empezaría a diluirse cuando se recuerda que Rousseau (1989) considera imposible para el Estado, como compuesto de particulares, entrar a dañar, como no lo podría hacer el cuerpo respecto de alguno de sus miembros. En todo caso, la aproximación al Estado ético de Rousseau, ya impone limitaciones a su ejercicio, de donde se edificaría con posterioridad, la idea del crimen de Estado.

El contractualismo hobbesiano, no rechaza la violencia. Al contrario, diferencia la violencia justa de la injusta (Hobbes, 2005). Por ello, Grüner (2000) rechaza la ficción de tranquilidad del contractualismo, en un análisis que revela que aún desde este diseño, el crimen de Estado podría presentarse como una función del Estado:

$\mathrm{Y}$, de todas maneras, la -ciertamente operativa- ficción contractualista puede tomarse por su reverso lógico, para decir que, aún cuando admitiéramos la discutible premisa de que la política es lo contrario de la violencia, los cadáveres son la condición de posibilidad de la política: en el dispositivo teórico contractualista (véase Hobbes) el Soberano necesita de los cadáveres para justificar su imposición de la Ley; de manera un poco esquemáticamente foucaultiana, se podría decir: la política produce sus propios cadáveres, la Ley produce su propia ilegalidad, para naturalizar su (como se dice) "imperio"; pero inmediatamente requiere que este origen sea olvidado: de otra manera, no podría reclamar obediencia universal, puesto que la violencia es del orden de lo singular, del acontecimiento reiterado pero intransferible, del límite en que el efecto sobre los cuerpos se sustrae a la Palabra (p. 146).

A pesar de ubicarse desde una tradición diferente, el crimen de Estado no se reconocería en Hegel (2000) por la vinculación directa que hace entre sociedad civil y Estado a través de la figura del espíritu. Esta lectura también exige un Estado ético, por lo que puede también constituir un antecedente de la posterior consideración del crimen de Estado.

Ante estas posturas, se tiene en Foucault una razón de Estado que se ensancha y autolimita por el vínculo Derecho- economía, por lo que resta determinar la razón por la cual el Derecho se ha convertido, bajo la hegemonía, en instrumento de ampliación de la razón de Estado, con tal intensidad que se ha construido la criminalidad de Estado como un concepto de la modernidad.

Bajo la promesa de la libertad y mediante el uso de sus paradojas, la modernidad capitalista ha instalado la razón instrumental. Esto podría coincidir con posturas propias de una concepción centro-periferia o Norte-Sur como la de Dussel (2000), quien si bien no comparte muchas de las conclusiones de la Dialéctica de la Ilustración, reconoce que frente a las promesas, la modernidad ha intentado justificar "una praxis irracional de violencia" (p. 48). Para Villoro (1992) el concepto de función es un atributo de la modernidad, que condensa las relaciones que rigen entre las cosas y entre los seres humanos. Desde allí, la violencia de Estado puede considerarse una función del sistema hegemónico moderno, como una forma de relación con cierta tendencia a la permanencia, que se media a través del poder. Ello se corroboraría con Calveiro (2012) quien resalta que la violencia estatal es el núcleo duro del sistema hegemónico, sintetiza las características de las formas específicas de organización de poder y "visibiliza sentidos y lógicas que circulan en lo cotidiano" (p. 15). Pero en el contexto de la modernidad capitalista, debe reconocerse con Naomi Klein (2007), que el modelo hegemónico de libremercado capitalista, precisa "condiciones autoritarias" (p. 33). Entonces, la violencia estatal tendrá expresiones tan diversas como el estadio de la modernidad en donde tengan lugar, y reflejarán visiones culturales y sociales determinadas. Ello también se aprecia con particular intensidad con el proceso de selección de víctimas, como se revisará en otro lugar.

La ampliación de la razón de Estado es aparejada con la construcción y utilización de la razón instrumental para construir la criminalidad de Estado. No podría ser menos en un escenario gestado a partir de la ilustración, que como señala Žižek (2011) tiene una inclinación totalitaria, por lo que campos de concentración y genocidios son una síntesis finalista negativa de la historia occidental. De tal contundencia es dicha correlación en el autor esloveno que encuentra que la violencia es "el complemento necesario del poder (...) [el cual] está presente siempre en la raíz de cualquier relación de violencia en apariencia apolítica"( p. 123). En un sentido, un tanto diverso, Bauman (2011) señala que el holocausto en tanto 
sociedad organizada cumpliendo una especial tarea, el "asesinato en masa a escala gigantesca", como aparato burocrático, constituye un efecto, pero no la síntesis de la modernidad: "demostró su preocupación por la corrección en los trámites burocráticos, por las sutilezas de la definición exacta, por los pormenores de las regulaciones burocráticas y por la obediencia a la ley". (p. 35)

Una primera respuesta al interrogante se encontraría de nuevo en la conexión Derechoeconomía, que presenta un elocuente ejemplo en el funcionamiento de la justicia penal. Foucault (2000) utiliza el concepto de homo æconomicus, creación de Adam Smith (1794), como constructo del hombre salvaje o presocial, propio del estado de la naturaleza. Así, distingue el ser humano presocial, y el salvaje creado por los economistas, como seres humanos salvajes. El homo æconomicus es una expresión de biopolítica que como persona es esencialmente gobernable, también constituye la grilla de inteligibilidad para gubernamentalizar el comportamiento de los individuos, por lo que se sintetiza en una racionalidad donde los indicadores del mercado se extienden "a todas las dimensiones de la vida política, cultura, social y humana" (Foucault, 2007).

La estimación del poder público en términos de mercado y el análisis de los comportamientos no económicos, resultaron de interés para el neoliberalismo, encontrando que la "ley es la solución más económica para castigar bien a la gente y que el castigo sea eficaz" (Foucault, 2007, p. 288). Por ello se propusieron mecánicas procesales para obtener el castigo y eliminar ciertas conductas bajo el principio de economía: El homo penalis es un homo æconomicus. (p. 288) En dicho entorno, el homo æconomicus tiene a su cargo el enforcement of law, que entre otros, constituye el conjunto de instrumentos de acción para dar realidad social y política a la prohibición en la ley, que se tolera, proporcionalmente a partir de la teoría neoliberal del consumo (Foucault, 2007).

Este homo penalis como homo æconomicus se traslada al Estado donde se instalan los intereses de quienes dominan bajo sus ventajas. En efecto, el crimen de Estado es un fenómeno de la modernidad (Kauzlarich, Mullins, \&Matthews, 2003), y si se considera que la soberanía es característica central del Estado moderno,
(Bavaresco, 2003) el crimen de Estado es una tecnología del poder. Si bien debe reconocerse que comporta dificultad aceptar que siendo el Estado productor del Derecho, pueda excusarse cuando se trasgrede el Derecho producido o reconocido. Dicha conclusión se aplica tanto a la acción del Estado como estructura, o a través de sus integrantes. Desde Kant (2008), tampoco sería aceptable, pues rompería con su lógica de comprensión del Derecho como conjunto de condiciones delimitadoras, entre los arbitrios humanos, en virtud de la ley general de la libertad.

La existencia de los crímenes de Estado refuerza la idea de que el Estado y su Derecho no se fundan en una ley general de la libertad, sino en la lógica de poder como lo corrobora el Derecho Internacional, aun cuando el surgimiento de la categoría de crimen de Estado se conecte con la idea de humanidad, como supuesto regulador del poder político. En dicho sentido Foucault (2012b) señala que en realidad, el discurso de humanización no tenía como referente al reo, sino a su público, por lo que la conexión entre economía y la política viabilizaron el tránsito hacia "castigos humanos", así: "Esta racionalidad 'económica' es la que debe proporcionar la pena y prescribir sus técnicas afinadas. 'Humanidad' es el nombre respetuoso que se da a esta economía y a sus cálculos minuciosos" (p. 106).

Foucault (1996) alude en dicho contexto a la tragedia del poder y del control del poder político. A partir de la imagen edípica, señala la discusión entre el poder y el saber en una imagen profundamente evocadora de la criminalidad de Estado: "El tirano griego no era simplemente quien tomaba el poder; si se adueñaba de él era porque detentaba o hacía valer el hecho de detentar un saber superior, en cuanto a su eficacia, al de los demás" (p. 54). La racionalidad del Estado en tanto aglutinador del saber social en Ihering (2006), se transforma en Foucault en la constatación del crimen de Estado como representación del poder, un saber y una eficacia. Un poder autodenominado como saber, que encierra eficacia para nombrar sus ilícitos a través de la impunidad, como diría Ihering (2006): "los hechos salvadores de la violencia del Estado. (...) el juicio sobre ellos está en su éxito; del foro del derecho que los condena, apelan al tribunal de la historia"(p. 185). Poder, saber y eficacia para idear, ejecutar, e ignorar la ocurrencia del crimen; elementos constitutivos de la criminalidad de 
Estado recopilados en la sentencia condenatoria de Fujimori en el Perú (Corte Suprema de la República, p. 538 s.s.). El reconocimiento de un poder de Estado que define el del Derecho, que además ha puesto en crisis el concepto moderno de derecho penal, como advierte Zaffaroni (1993):

Los fuegos artificiales de las teorías que legitiman la pena asignándole funciones manifiestas falsas (prevención, de cualquiera naturaleza) no logran ocultar las contradicciones cada vez más profundas $\mathrm{y}$ deteriorantes de profesores, jueces y abogados. El discurso en crisis no es una mera cuestión de palabras, sino que implica una grave crisis del poder jurídico. Nos vamos quedando vacíos, sin discurso (o con uno que sabemos falso, que es lo mismo), frente al poder de las restantes agencias no jurídicas que avanza arrolladoramente (policiales, administrativas, políticas, de comunicación masiva, etc.)

Las teorías positivas de la pena (preventivas) no han hecho otra cosa que legitimar el poder que nos engulle. El discurso jurídico-penal es la justificación de un ejercicio de poder punitivo que ejercen otros, no los juristas ni las agencias jurídicas. (p. 11 y 12)

La reconstrucción y sostenimiento del poder a través del crimen de Estado en la modernidad, también involucra el papel del testigo. En el mito edípico el humilde testigo podía "por sí sólo, por medio del juego de la verdad que vio y enuncia, derrotar a los más poderosos" (Foucault, 1996, p. 63). Ello se transforma en el crimen de Estado, donde atestigua el poder como en la prueba judicial feudal que Foucault (1996) describe como mecanismo para establecer la fuerza y de conformidad con ella, la razón. Esto es, un ejercicio ritual o simbólico de la guerra

Con estas aclaraciones sobre la vinculación Estado, poder, economía y guerra; es necesario destacar dos de las dimensiones del fenómeno nazi. Una alusiva a la expansión ilimitada de este sistema en el mundo, y otra relativa a los efectos de la constitución del denominado enemigo interno: los comunistas, los judíos, el pueblo Rom, que pueden sintetizarse en la idea del judío bolchevique (Feierstein, 2008). En el primero de los órdenes, para autores como Hobsbawm (1998) la guerra era irresistible, en tanto "la expansión y la agresión eran una parte consustancial del sistema [nazi]"(p.159). La discusión se presenta en relación con el ataque contra el pueblo alemán, donde se ubica el concepto moderno de crimen de Estado que aquí se analiza. Por ello, la Segunda Guerra Mundial y en general, la lucha contra el fascismo, a pesar de sus particulares pretensiones hegemonizantes, podrían constituir una lucha para conseguir una sociedad mejor (Hobsbawm, 1998).

En contraste, Žižek (2006) señala con Hegel que la democracia absoluta solo se actualiza en tanto terror: "Tenemos, pues, que elegir en este punto: ¿Aceptamos la imperfección estructural, no sólo accidental, de la democracia, o asumimos también su dimensión terrorista?"(p. 224). Juan Carlos Bayón (2008) se pregunta si es posible la superación del Estado nación y si ello es deseable para configurar una democracia más allá del Estado. Más allá de discutir la posible dimensión terrorista del crimen de Estado, -hecho indiscutible para el Derecho argentino bajo la noción de Terrorismo de Estado o de Estado genocida (Andreassi, 2005), y concepto apropiado en la jurisprudencia interamericana, como se revisará en otro momento-; debe reconocerse que en el Derecho Internacional se limita normativamente la actuación del Estado. El nuevo cuestionamiento es: ¿Cómo se definió dicha transformación desde una comprensión de Estado bajo el absolutismo, hacia el Estado que se limita en el Estado de Derecho o en el Estado Social de Derecho? La respuesta es sencilla: A través de un producto de la modernidad, que al unísono presenta en la actualidad vocaciones de hegemonía como de contrahegemonía.

El Estado, como referente unificador de normas, centra la seguridad en el Derecho y, a partir de sus fórmulas organizativas constitucionales, generó modelos de derechos humanos que corresponden en su visión hegemónica occidental, a modelos constitucionales: Desde los derechos humanos ahistóricos del modelo continental, hasta los derechos humanos historicistas del modelo inglés (Fioravanti, 1996). Un producto de la modernidad que se expandió tras la Segunda Guerra Mundial. Lógicas de derechos humanos que se presentarían como límites al Estado para afirmar, en términos de Ihering, su moral práctica. Asiste entonces razón a Hobsbawm (1998) cuando señala que las grandes transformaciones entre la Primera Guerra Mundial y el inicio del siglo XXI, evidencian 
una contradicción entre la unidad operativa mundial y el individualismo asocial. Pero también revelan un acentuamiento de las características definitorias de la modernidad. La sociedad que de allí emergió, estuvo siempre implícita en la teoría de la economía capitalista, entonces el capitalismo como fuerza revolucionaria continua, que acabaría por desintegrar los viejos valores y relaciones sociales (Hobsbawm, 1998).

En estas condiciones es posible concebir que los contenidos de la noción de crimen de Estado, surgieron para el Derecho en el segundo momento histórico del siglo XX. Dicha ocasión se inicia, como lo reitera Hobsbawm (1998), con la caída del régimen nazi y a partir de la "insólita y temporal alianza del capitalismo liberal y el comunismo" (p. 17), enfrentados contra el fascismo bajo el antifascismo. Tras él, viene el momento de la bipolaridad iniciado con la Primera Guerra mundial donde las potencias se lanzaron bajo la pretensión de control hegemónico mundial (Calveiro, 2012). En el contexto de esta bipolaridad, con posterioridad a la Segunda Guerra Mundial se pretendió la creación de una organización internacional abanderada de la paz mundial. A pesar de las pretensiones diferentes de las dos grandes potencias para su consolidación, se obtuvo la creación la Organización de las Naciones Unidas (Roberts, 2010), en el contexto del reconocimiento de "la matanza, la tortura y el exilio masivo" como "experiencias cotidianas que ya no sorprenden a nadie"(Hobsbawm, 1998, p. $60)$. Un escenario de realidad inverso al proceso de "humanización" del que se había hablado a partir de la Ilustración:

Recuerda Ferrajoli (2001), a propósito de abordar el problema de los fundamentos del derecho a castigar, que fue en el terreno del Derecho penal donde, en los siglos XVII y XVIII, la filosofía del iusnaturalismo racionalista libró sus batallas contra el despotismo represivo e inquisitivo del Antiguo Régimen y fueron definiendo los valores de la civilización jurídica moderna y las líneas maestras del Estado de Derecho: el respeto a la persona humana, los valores de la vida y de la libertad personal, el nexo entre legalidad y libertad, la tolerancia y la libertad de conciencia y de expresión y la primera función del Estado protector de unos derechos. Posteriormente, diversos factores contribuyeron a intentar desmoronar aquel edificio de la Modernidad.
El autor italiano menciona, entre los más relevantes, el repliegue reaccionario del pensamiento liberal de fin del siglo XIX, una burda epistemologìa positivista basada exclusivamente en la aproximación acrítica al solo "derecho que es"; una suerte de paradójica "naturalización "del Derecho penal como fenómeno externo e independiente de la obra de los juristas, suceptible de conocimiento o a lo sumo de explicación, pero no de justificación o de deslegitimación; y por ello la reducción de su legitimación externa o política a la interna o jurídica o la confusión de su justicia con su mera existencia (Rivera Beiras, 2004a, p. 287 y 288).

En estas anteriores condiciones, la víctima del crimen de Estado es víctima de quien determina, condiciona y sostiene el Derecho. Frecuentemente (casi siempre) será víctima del Derecho como expresión de poder, como forma ritual de guerra. Como en el derecho penal del suplicio, la víctima es retirada del escenario por el poder que solo usa el concepto de daño para reafirmarse, como a través del mecanismo de las confiscaciones, mediante la cual "se pretende la reparación de la ofensa cometida contra el soberano, el Estado, la ley" (Foucault, 1996, p. 77). Ello explicaría porqué el Derecho Penal se ha pretendido como escenario de intocable soberanía: "en el derecho monárquico, el castigo es un ceremonial de soberanía" (Fou cault, 2012b, p. 135). Criminalidad de Estado que se ejercita y viabiliza a través de la selección y la impunidad, como se corrobora al escuchar al hijo del abogado y defensor de los derechos humanos Eduardo Umaña Mendoza, cuando rememora las gestiones de la Fiscalía en el proceso penal adelantado por la muerte de su padre:

Un grupo de personas sería imputado y juzgado por supuestamente haber estado implicado en el asesinato de mi padre. Como era de esperarse, uno a uno los acusados fueron absueltos sin mucha controversia. Luego de eso no ha habido nada o, mejor, como la Fiscalía Segunda Especializada de Derechos Humanos me corregía en la respuesta a un derecho de petición de impulso del proceso: 'No es que la Fiscalía haya estado inactiva como lo asegura usted en su escrito, sino que desgraciadamente la labor investigativa desplegada en torno al caso ha sido infructuosa'. Sin frutos, marchita como 
la muerte, en coma como la ausencia. (Umaña Hernández 2013).

La criminalidad de Estado como una versión del poder a partir de la modernidad, evidencia que la relación del poder sobre el cuerpo se ha transformado (Foucault, 2012b), y que el Derecho buscando su legitimación, reconoce la posibilidad de que el propio Estado entre en el terreno de la comisión de delitos. La pretensión del Estado moderno es mostrarse como racional y ético, cuando continúa siendo un espejismo (Gallardo, 2009; Gramsci, 2005a). Situación que llama la atención sobre el debate de administración de justicia en la contemporaneidad: El Estado denominado ético, encuentra un discurso que confirma su lógica de soberanía hacia adentro y afuera, diciendo que se afirma en una racionalidad particular: Los Derechos Humanos. Esa racionalidad en el concierto internacional se revela en términos de Boaventura de Sousa Santos (2005), como una dimensión hegemónica de los derechos como globalización desde arriba, trayendo consigo, incluso a pesar de la globalización, a un Estado maximizado en la aplicación del Derecho penal. El Derecho tiene una vocación de espejismo para enfrentarse al Estado. Los intereses aglutinados en el Estado, en ejercicio de su control, utilizan el castigo/suplicio frente a un enemigo que delimita y construyen previamente. Esta es una consecuencia directa del pilar de regulación dentro del paradigma de la modernidad: Obligación vertical entre determinado tipo de ciudadanos y el Estado a través del Derecho.

La resolución en propuesta emancipadora, propondría una revisión, que no se agota en este documento: ¿Qué elementos de edificación desde un pensamiento crítico del Derecho, entregaría el procesamiento del Estado y sus estructuras en el entorno de los crímenes fundamentales del DPI?

\section{EJERCICIOS DE DISCRIMINACIÓN: EL CRIMEN DE ESTADO COMO CATEGORÍA PARA EL DERECHO}

Intereses diversos dentro de la modernidad, generan tipos distintos de criminalidad de Estado en un sentido general: una fundacional que puede coincidir, por ejemplo, con el momento del arribo europeo a América, y una criminalidad reconfiguradora o reorganizadora, que también obedece a la interacción entre la realidad y la pretensión del Derecho según la ética del Estado liberal. Dentro de esta comprensión se ubica también a Foucault (2000) cuando alude a la existencia de un genocidio colonizador que puede englobar tanto fenómenos fundacionales como reorganizadores, donde el racismo es herramienta del Biopoder: "Cuando haya que matar gente, matar poblaciones, matar civilizaciones, ¿cómo será posible hacerlo en caso de funcionar en la modalidad del Biopoder? (...) A través de los temas del evolucionismo, gracias a un racismo"(p. 232). Por ello, considerar los conceptos de criminalidad de Estado fundacional y criminalidad de Estado reorganizadora, que emergen de la teoría de Daniel Feierstein (2008), no implica adaptar de manera directa su concepto de genocidio. Deben determinarse entonces los escenarios de tránsito, semejanza o diferenciación del concepto de genocidio bajo la sociología y el de criminalidad de Estado que subyace en el Derecho.

El genocidio reorganizador puede explicarse a partir de la pretensión de creación de "una nueva legalidad, una nueva escala de valores y de normas sociales", como método de ejercicio de poder (Andreassi, 2005), o lo que es lo mismo como aplicación de la biopolítica en la modernidad. Dicho genocidio se sustenta por tanto en la utilización del miedo para el sostenimiento o la reimplantación de determinados intereses hegemónicos. Se establece tras la determinación o identificación de un sujeto (individual o colectivo) como enemigo/víctima, y la aplicación de una política preestablecida, que puede ser "legal" en cuanto su adscripción al Derecho nacional, o ilegal, e incluso generarse a partir de una combinación de ellas. Carvajal Martínez (2010), advierte: "se crearon medidas legales bajo la protección de la figura del orden público que terminaron por recortar derechos y libertades, esta misma normatividad jurídica permitió la persecución y represión sobre las organizaciones e individuos que consideraba como sus enemigos" (p. 260 y 2008).

Precisamente aquí se observa el principal puente entre el concepto de genocidio como práctica social y la criminalidad de Estado, y su diferenciación del tipo penal de genocidio como crimen internacional. En el pasado se consideró que el tipo de genocidio y el terrorismo de Estado se diferenciaban en la gran escala de crímenes que caracteriza al primero (Garzón Valdés, 2001, p. 141). Pero la postura debe abandonarse al 
valorar que el tipo de genocidio desde el Derecho Internacional, no exige un alto número de víctimas para constituirse, sino la intención de destrucción total o parcial de un grupo (UN, 1948; CIJ, 1951). Por su parte, la criminalidad de Estado no se agota en los ataques contra el derecho a la vida, por lo que es necesario reconocer que la criminalidad de Estado configuraría un género, del cual el genocidio como práctica social, y como tipo penal internacional, constituirían su especie. El vehículo central entre estas figuras se encuentra constituido por el mecanismo de control mediante el miedo. Garzón Valdés (2001) se separaría parcialmente de esta comprensión, al señalar que a diferencia del terrorismo de Estado, la destrucción física en la persecución nazi, o en la masacre de comunistas en Indonesia, no buscaba sostener el miedo en las personas que no hacían parte de los grupos objeto de selección, de donde concluye que este no es una condición necesaria del genocidio:

El terrorismo de Estado es una forma de ejercicio del poder estatal cuya regla de reconocimiento permite $\mathrm{y} / \mathrm{o}$ impone, con miras a crear el temor generalizado, la aplicación clandestina, impredecible y difusa, también a personas manifiestamente inocentes, de medidas coactivas prohibidas por el ordenamiento jurídico proclamado, obstaculiza o anula la actividad judicial y convierte al gobierno en agente activo de la lucha por el poder (p. 146 y 147).

Desde el triunfo del capitalismo, con la revolución industrial (Hobsbawm, 1998) y hasta la actualidad, se han desarrollado numerosos genocidios reorganizadores fundados en procesos de selección, pero han tenido uno de sus momentos más reconocidos en el proceso genocida de la Segunda Guerra Mundial. A la par, otros procesos genocidas fueron ignorados largo tiempo por occidente, como el genocidio Armenio o el Palestino, este último denunciado desde el propio informe Whitaker (ONU- Whitaker, 1985). El genocidio armenio (1915-1916) que cobró aproximadamente más de un cuarenta por ciento (40\%) de la población Armenia en el actual territorio de Turquía, fue reconocido finalmente en el año de 1985 con la aprobación del Informe Whitaker por la Comisión de Derechos Humanos de Naciones Unidas hizo. Este genocidio había sido retirado del documento final del Informe Ruhashayankiko en el año de 1979 (ONU,
Ruhashayankiko, 1979), al parecer por la presión del gobierno Turquía (Inazumi, 2005). El informe Whitaker refleja que el gobierno turco, asumió la tesis de negación del genocidio (ONU- Whitaker, 1985).

No obstante, el genocidio nazi permite asociar una nueva configuración del proceso de selección, cuando los otrora genocidas, y con mayor contundencia, su pueblo, se convirtieron en nuevo objeto de selección. Este transcurso ya no se vinculó con sus acciones sino con su identidad, incluso nacional. Entonces quienes se adscribían al bando perdedor, o en cualquier forma estaban vinculados a ellos, empezaron a ser protagonistas de un proceso de aniquilamiento que no se limitó al silenciamiento, pues fueron: "prácticamente borrados de la historia y de la vida intelectual, salvo en su papel de 'enemigo' en el drama moral universal que enfrenta al bien con el mal" (Hobsbawm, 1998, p. 14). Ello corrobora a Sandoval Huertas (1977) cuando destaca que la principal característica del estigma como hecho de violencia es su contenido clasista, su objeto preferido son los "individuos pertenecientes a sectores dominados, o marginados del proceso de producción" (p. 52). Los ejemplos están en permanente actualización, como en Rajagopal (2003) analizando las lógicas del enemigo interno y de estigmatización del pensamiento diferente incluso en la academia, o Soares y Guindani (2007), estudiando la violencia de Estado de la policía en Brasil:

(...) [E] n 2003, en el estado de Río de Janeiro, 1.195 personas fueron asesinadas por la policía (más de 65\% de ellas mostraban signos inequívocos de ejecución). En 2004, las víctimas fatales fueron 984 y en 2005 el número subió a 1.087. En 2006, solo en el primer semestre, se registraron 520 civiles muertos por la policía. Casi todos fueron jóvenes negros habitantes de las favelas.

(...) Durante esos operativos, la policía no tomó prisioneros ni aceptó la rendición de los sospechosos. En general, estos números aterradores describen un verdadero genocidio, resultado de una política deliberada de exterminio, ilegal y arbitraria, basada en la creencia de que le corresponde a la policía identificar al sospechoso, juzgarlo, sentenciarlo a la pena capital y ejecutarlo, todo en un mismo momento. 
Es verdad que la brutalidad letal de los policías parece insuperable. Pero lo notable, lo que revela la barbarie del Estado, es que estas prácticas persistan sin que el Ministerio Público o la Justicia intervengan y sin que la opinión pública imponga a los líderes políticos una reacción. Y es más notable todavía si se considera que la táctica de las confrontaciones y de las incursiones bélicas, que iguala a las favelas con un territorio enemigo a devastar, no ha generado ningún beneficio para la seguridad pública (p. 62).

Se evidencia así el crimen de Estado como venganza signada por el poder. Ejercicio de poder político, que presentándose bajo el mito del Estado ético, utiliza la negación y la supuesta insularidad (la conocida retórica de agentes de Estado y no Estados), para traslapar una verdadera tecnología de poder. Esa tecnología de poder transita a través de la discriminación, como lo resalta Zaffaroni (2011) en relación con el poder punitivo, que no reconoce un trato correspondiente a personas, sino como "entes peligrosos o dañinos. Seres humanos señalados como enemigos de la sociedad" (p. 11). Esta correspondería con la discriminación primaria, que Tugendhat (1992) entiende como la discriminación aristotélica que señala la existencia de diferencias básicas del valor de diferentes tipos de personas, y que debe ser rechazada: "si no hay discriminación primaria (...) los derechos fundamentales se distribuyen de una manera igualitaria, y en parte por esto se llaman derechos humanos" (p. 31). Contrasta con la distinción secundaria que exigiría distinciones de distribución por tener el mismo respeto (valor) por todas las personas, con fundamento en la necesidad, el derecho particular y el mérito. Como expresión de la discriminación primaria, Feierstein (2008) con fundamento en Chalk y Jonassohn, sintetiza cuatro modelos de genocidio, en otra idea que conecta su concepto de genocidio reorganizador y la criminalidad de Estado, con tal contundencia que podrían consistir en su tipología: (i) los que buscan eliminar una amenaza real o potencial a la sociedad; (ii) los que diseminan el terror entre enemigos reales y potenciales; (iii) los genocidios implementados para adquirir riqueza económica; y (iv) los establecidos para desarrollar una creencia religiosa, una teoría científica o una ideología. (p. 89) En estas expresiones subyace lo que Tugendhat (1998) denomina la incapacidad de construcción de conciencia colectiva como enfermedad, que constituye una reacción violenta que impide "despreciar las demás identidades culturales y nacionales, y de ahí llegar a negar incluso que los demás también son personas" ( $p$. 36).

En efecto, para entender la inclemencia del crimen de Estado como expresión de la violencia estatal, resultan de utilidad los conceptos de violencia y de crítica a la violencia desde otra víctima del genocidio nazi: Walter Benjamin.

El pensador alemán caracteriza a la violencia como un medio cuya crítica se ejerce en la relación con el derecho y la justicia (Benjamin, 1971). Distingue entre la tesis iusnaturalista de la violencia que señala como jurídicamente legítima a la violencia adecuada "casi exclusivamente a los fines naturales", que conduce a una casuística sin fin; y las tesis de derecho positivo que consideran "al poder en su transformación histórica", pero es insuficiente, porque aun cuando diferencia diversos géneros de violencia, es necesario hacer crítica del Derecho positivo. (p. 172). A partir de allí concluye que el criterio de la crítica a la violencia debe ser externo a las dos tesis, y el Derecho debe ser considerado desde la filosofía de la historia (Benjamin, 1971). Por ello llama a revisar los medios de la violencia, sin limitarse a considerar la llana existencia de violencias legítimas e ilegítimas o con fines justos e injustos, pues el Derecho como expresión de poder impide arribar a un reconocimiento histórico universal de sus fines. En este contexto, Benjamin empieza a delinear los contornos que definen el crimen de Estado, desechando la idea de un mal individual:

a. Reconoce el carácter fundacional y reorganizador de la violencia en su relación con el Derecho. Señala una violencia que tendría lugar fuera del Derecho al vulnerar el monopolio de la violencia por una persona aislada, que incluso pueda ser objeto de admiración popular. Una segunda especie de violencia se presentaría como justa según el ordenamiento jurídico, como el ejercicio del derecho a la huelga, que al momento de elaboración de su artículo Para una crítica de la violencia, solo podría ser ejercida por la clase obrera y los Estados, aun cuando "es posible definir en ciertas condiciones como violencia, incluso una actitud asumida en ejercicio de un derecho" (Benjamin, 1971, p. 178). 
b. Señala que tanto en el ejercicio de la guerra como en el derecho de huelga, se observan sujetos jurídicos que sancionan poderes, por lo que reconoce en toda violencia, un carácter de creación jurídica (Benjamin, 1971). De esta forma, no solo se corrobora el proceso de selección desde el Derecho, sino que se soluciona la aparente disyuntiva en concebir la violencia estatal, cuando es el Estado quien sanciona el Derecho:

(...) [E]l derecho limita el uso de los medios enteramente no violentos, debido a que éstos, por reacción, podrían engendrar violencia. Tal tendencia del derecho ha contribuido también a la concesión del derecho de huelga, que contradice los intereses del Estado. El derecho lo admite porque retarda y aleja acciones violentas a las que teme tener que oponerse (p. 186).

Es en este escenario que hace crítica del imperativo categórico kantiano, a partir de una tácita detracción de la criminalidad de Estado. Así sostiene que en realidad el derecho positivo busca promover el interés de individuos aislados para conservar el orden. Por ello concluye que no solo el proceso de selección, sino además, la esencia conflictual del Derecho, se origina en la violencia como "poder que funda o conserva el derecho" (Benjamin, 1971). "Creación de derecho es creación de poder, y en tal medida un acto de inmediata manifestación de violencia" (p. 183.). Por la violencia creadora del Derecho, Benjamin resalta la necesidad de imponer límites al poder, y a su selectividad.

Como ocurre bajo el proceso penal (Foucault, 2012 b) la selección se construye a partir de características que no coinciden de forma necesaria con la cultura, la religión y la raza (Feierstein, 2008) o los tres criterios centrales de la concepción restrictiva de la Convención contra el Genocidio de 1948 (UN, 1948). Para corroborar el aserto, debe advertirse con Correas (1988) que un punto crítico de la sociedad capitalista implica el punto de vista de quienes no se benefician de la distribución de bienes materiales y culturales que dicha sociedad produce. De allí que considerando la existencia de "los no beneficiados" y los dominantes (Correas, 1988), el Derecho arribó a la actualidad bajo una idea bifronte: expectante frente a la criminalidad contra quienes define como no beneficiados, y en tanto herramienta de control de ese grupo identificado como las víctimas del poder: las víctimas de los crímenes de Estado:

El hecho de la hegemonía presupone indubitablemente que se tienen en cuenta los intereses y las tendencias de los grupos sobre los cuales se ejerce la hegemonía, que se forma un cierto equilibrio de compromiso, es decir que el grupo dirigente hará sacrificios de orden económico-corporativo, pero es también indudable que tales sacrificios y tal compromiso no pueden concernir a lo esencial, ya que si la hegemonía es éticopolítica no puede dejar de ser también económica, no puede menos que estar basada en la función decisiva que el grupo dirigente ejerce en el núcleo rector de la actividad económica (Gramsci, 1980, p. 40 y 41).

El concepto de genocidio ayuda a comprender cómo se desarrollan los procesos de selección específica de la criminalidad de Estado. Feierstein (2008) establece tres elementos principales: (i) Se trata de una selección solo en apariencia racista. (ii) El genocidio corresponde a un proceso previo de selección. Finalmente, (iii) Se presenta como una tecnología de poder, a partir de la cual la hegemonía construye alteridades e identidades. Entonces algunos genocidios signados por un supuesto carácter étnico, sin considerar su aspecto político, señalan "una decisión tanto argumentativa como ideológica de priorizar los elementos étnico religiosos en la configuración de alteridad de las víctimas"(Feierstein, 2008, p. 18), postura que corrobora Andersen (2006). En similar sentido, bajo la razón imperialista el concepto de racismo es un instrumento de acusación (Bordieu y Wacquant, 2001; Quijano, 1999). Las teorías de las relaciones raciales son transfiguraciones conceptualizadas de estereotipos que pretenden justificar la dominación, como lo advierten Bordieu y Wacquant (2001):

El que en el transcurso de los últimos años la sociodicea racial (o racista) haya podido "mundializarse", perdiendo a la vez sus características de discurso justificador de uso interno o local, es sin duda una de las pruebas más ilustrativas del dominio y la influencia simbólica que Estados Unidos ejerce sobre cualquier tipo de producción culta, principalmente a través del poder de consagración que detenta y el beneficio 
material y simbólico que procura a los investigadores de los países dominados la adhesión más o menos asumida o vergonzosa del modelo procedente de Estados Unidos (p. 29).

Reconociendo los elementos que inciden en la conformación de la dimensión de lo real (imaginario, simbólico, y real), Žižek (2002) señala que "in Nazi anti-Semitism, the Jew as the excremental Object is the Real that masks the unbearable "structural" Real of the social antagonism" (p. 255) ${ }^{1}$. Asimismo, con fundamento en los estudios de Arendt, Feierstein resalta que los marcos ideológicos, sumados al racismo como configurador, generan la imagen del enemigo como paradigma ideológico.

En auxilio de esta postura, debe recordarse con Althusser (2005) que el Estado tiene múltiples aparatos que se combinan en la vida cotidiana siguiendo la hegemonía: los aparatos ideológicos se diferencian de los represivos en que generalmente no pertenecen por completo al dominio público, y porque mientras estos funcionan principalmente con violencia, los aparatos ideológicos del Estado lo hacen principalmente de forma ideológica. A través de aparatos ideológicos y represivos, el Estado expone la intencionalidad hegemónica que, como diría Feierstein (2008), subyace a los procesos genocidas, y su configuración como una específica tecnología de poder. Los aparatos del Estado confluyen en la permanente elaboración del proceso de selección, que no cesa durante la ejecución del crimen de Estado, viabilizando tanto la impunidad cíclica, como la posibilidad de repetición. Feierstein destaca que la negación de la identidad de las víctimas constituye un proceso central en la búsqueda de la impunidad cíclica, que se sintetiza en la pretensión de su desarticulación política a través de múltiples escenarios: En primer lugar, bajo la vertiente irrealizada de la naturaleza igualadora (Correas, 2006), donde el reconocimiento como ser humano y como víctima, depende de intencionalidades hegemónicas, como puntualiza Correas (2006) al recordar los procesos de reconocimiento de la naturaleza humana en las mujeres, las naciones originarias, prolongándose hasta la actualidad:

1 En el antisemitismo nazi el 'judío' era el objeto excrementicio que oculta lo real 'estructural' del antagonismo social que resulta intolerable.
Los principios del siglo XXI, han mostrado que, para algunas democracias grandes, los árabes no son igualmente humanos que los occidentales, habida cuenta de que en el Irak de 2004 no se contabilizan los decesos musulmanes, sino solamente los de los soldados invasores. Tampoco se consideraron de naturaleza igual los prisioneros de Guantánamo, que pasaron años sin ningún aviso de que fueran considerados humanos, y a la muy gustosa paciencia de la mayoría de los miembros de la más grande democracia jamás habida. Y, aunque no es considerada una democracia, la culta Alemania nazi no percibía ninguna igualdad de naturaleza entre sus miembros y los judíos, los gitanos, los comunistas (y quién sabe qué hubiera pasado si hubiesen llegado a América Latina)" (p. 273 y 274).

Asimismo se busca la desarticulación política de las víctimas, limitándolas a las víctimas inocentes, apáticas en lo político, silenciosas en su compromiso, o signándoles como víctimas que se han procurado a sí mismas, estableciendo de nuevo, la característica del silencio como vehículo de supervivencia. Finalmente la desarticulación política se pretende negando la calidad de víctimas de determinado escenario de criminalidad, particularmente de la estatal, para reconducir el escenario del crimen proveniente de un mal absoluto, que en todo caso no puede ser el del Estado.

Se destaca que esta dinámica del genocidio como práctica social, igualmente caracteriza la ejecución de la criminalidad de Estado. Debe considerarse la pretensión de la razón instrumental de comprender la sociedad como un jardín del cual deben desterrarse las minorías que se conciben como una especie de maleza. A partir de allí se empieza a concebir la seguridad como un proceso de inmunización, como algunos autores han encontrado que tuvo lugar la llamada política de seguridad democrática en Colombia, a partir de la concepción de sociedad orgánica y de la necesidad de "extirpar, sacar del cuerpo" el proceso que afecta su "salud" (Díaz Gómez, 2012, p. 173). Ello coincide con la acéptica pretensión nazi y puede explicarse con René Girard (1986):

Los perseguidores siempre acaban por convencerse de que un pequeño número de individuos, o incluso uno solo, puede 
llegar pese a su debilidad relativa a ser extremadamente nocivo para el conjunto de la sociedad. La acusación estereotipada permite y facilita esta creencia y desempeña un papel mediador. Sirve de puente entre la pequeñez del individuo y la enormidad del cuerpo social. Para que unos malhechores, por diabólicos que sean, consigan masificar a toda la comunidad, han de herirla directamente en el corazón o en la cabeza, o bien iniciar el proceso a escala individual cometiendo crímenes como parricidios, incestos, etc., que provocan por contagio el cese de toda diferencia (p. 25).

En efecto el estereotipo es un proceso de categorización social que impone hegemónicamente un conjunto de creencias adquiridas y sostenidas en relación con un grupo social. Por ejemplo, se ha reconocido que los estereotipos de género, constituyen a la vez causa y consecuencia de la violencia contra la mujer (CIDH, 2001, 2013; Corte IDH, 2009, pár. 401; Montes Berges, 2008). No en vano el racismo constituye la expresión de los estereotipos y la discriminación, basados en el rechazo sustentado en una idea de amenaza (Montes Berges, 2008), y constituye un mecanismo de dominación social, una expresión de la colonialidad del poder (Quijano, 1999). Entonces, el proceso de selección y el estereotipo subyacen como fuerzas motrices de la selección que construye la criminalidad de Estado como se corrobora por Žižek (2008) al analizar el ocultamiento del antisemitismo nazi, donde las ideas "no son otra cosa que la forma misma de la apariencia". (p. 38) Justamente, visitando a Eduard Said, el pensador español Santiago Alba Rico señala que los procesos de construcción de otro a perseguir, se observan en múltiples lugares como discursos políticos o medios de comunicación, buscando justificar la aniquilación del pueblo judío y de pueblos como los musulmanes: “¿Qué hace falta para aniquilar al otro? Pues concebirlo primero como una unidad, y en segundo lugar como una unidad inasimilable" (Alba Rico y Guanche, 2012, minuto 38:18 ss). Said (1996) precisamente hace hincapié en la trascendencia de los procesos de selección, al determinar las guerras justas, por ejemplo, en lo atinente a la Primera Guerra del Golfo Pérsico, donde en las Naciones Unidas prevaleció la postura estadounidense de producir únicamente sanciones contra Irak. Ello se hizo con sustento en dos ideas nucleares arraigadas desde el pasado, el "derecho de la gran potencia a salvaguardar sus intereses distantes (...) [y] la de que los pueblos menos poderosos eran inferiores y gozaban de menos derechos, exigencias y moral" (p. 81). A conclusiones similares arriba Calveiro (2012), quien tras revisar el tránsito guerrerístico internacional desde la Primera Guerra Mundial a la actualidad, subraya que sus mayores víctimas (en aumento) constituyen población civil, esto es, existe un principio de discriminación de violencia que se acompaña (paradójicamente) de un criterio de selectividad: "se puede arrasar masivamente con la vida, siempre que sea la vida del Otro" (Calveiro, 2012, p. 22).

Estas consideraciones se actualizan en las cifras del genocidio del pueblo Palestino. La “Operación Muro Defensivo en 2002, había sido "la más importante desde la Guerra de los Seis Días de 1967" (ONU, CJDH, 2009, p. 49). Pero las cifras estimadas de víctimas civiles frente a las últimas operaciones de Israel contra Palestina, reafirman el genocidio que se está verificando. Se estima que desde la creación del Estado de Israel entre 1947 y 148, ha llevado a cabo aproximadamente diecisiete operaciones militares contra Palestina, que han tenido sus picos de horror en los años de 2008, 2012 y 2014 (Abc 2014). La “Operación Muro Defensivo" en 2002, dejó 497 palestinos muertos (ONU, CJDH, 2009), la "Operación Arco Iris" en 2004, dejó otro saldo de aproximadamente 50 palestinos asesinados (ONU, CJDH, 2014), cifra que se duplicó en la operación "Días de Penitencia" entre septiembre y octubre de 2004. La Operación "Plomo Fundido" se desarrolló en dos fases principales (aérea y terrestre), entre el 27 de diciembre de 2008 y el 18 de enero de 2009 (incluye la operación "Invierno Caliente") y el 27 de diciembre de 2008 y el 3 de enero de 2009 (ONU, CJDH, 2009). Entre enero y diciembre de 2008, alcanzó un número aproximado de 1444 víctimas mortales palestinas (AI, 2009a; ONU, CJDH, 2009), entre ellas, 300 niños y niñas (AI, 2009a), como señalaron las Naciones Unidas:

Las estadísticas sobre el número de palestinos que perdieron la vida durante las operaciones militares son dispares. De acuerdo con una amplia investigación de campo, organizaciones no gubernamentales (ONG) sitúan el número total de personas muertas entre $1.387 \mathrm{y}$ 1.417. Las autoridades de Gaza informaron de 1.444 víctimas mortales. El Gobierno de Israel considera que esta cifra fue de 1.166. 
Los datos proporcionados por fuentes no gubernamentales sobre el porcentaje de civiles entre las víctimas mortales son en general concomitantes y suscitan muy serias inquietudes sobre la forma en que Israel llevó a cabo las operaciones militares en Gaza (ONU, CJDH, 2009, p. 15).

La operación "Pilar Defensivo" se desarrolló entre el 14 y el 21 de noviembre de 2012, donde solo el primer día se llevaron a cabo doscientos ataques aéreos contra territorio palestino (Huffington, 2012) y para el 21 de noviembre de 2012, se habían registrado noventa y tres personas de nacionalidad palestina muertas y novecientas heridas (Palestinalibre, 2012). Desde los primeros reportes de Naciones Unidas sobre la incursión de Israel sobre Gaza a partir del 8 de julio de 2014, "Operación Margen Protector", las miles de víctimas palestinas eran principalmente civiles (Bbc, 2014; La Jornada, 31 julio 2014; Palestinalibre, 2014a), como resaltó Navy Pillay, entonces Alta Comisionada de las Naciones Unidas para los Derechos Humanos (Noticias RT, 2014). El 31 de julio de 2014, el Jefe de la agencia de las Naciones Unidas para los Refugiados Palestina, Pierre Krahenbuhl, sostuvo ante el Consejo de Seguridad de Naciones Unidas: "Creo que la población está al borde de un precipicio y llamo a la comunidad internacional a tomar las medidas necesarias para enfrentar esta situación extrema" (La Jornada, 2014). Se alcanzó a establecer un número aproximado de 2.122 personas palestinas muertas (TeleSur, 2014a; 2014) entre los que se cuentan 500 niñas y niños (Palestinalibre, 2014) y aproximadamente 10.500 heridas (Palestinalibre, 2014a; TeleSur, 2014b). Entre ellas, según cifras de la Organización Mundial de la Salud citada por Palestinalibre, se encuentran más de tres mil niños y niñas heridos, de quienes unos mil quedarán en condiciones de discapacidad o funcionalidad diferente (Palestinalibre, 2014). Cifras a las que se suman las de miles de refugiados, pues se destacó para el 22 de agosto de 2014: "La Agencia de Naciones Unidas para los Refugiados Palestinos en Oriente Próximo (UNRWA) ha indicado este jueves que el número de personas que se encuentran refugiadas en sus instalaciones en la Franja de Gaza ha ascendido a 280.000, lo que ha descrito de "cifra sin precedentes" (Palestinalibre, 2014a).

Se ha denunciado que la dirección de los ataques, principalmente contra la población civil, obedece a una estrategia prediseñada como ocurrió con los ataques de Israel contra El Líbano (TeleSur, 2014c). Más allá de ello, resulta insoslayable reconocer que esta corresponde, a la postre, al sector poblacional principalmente atacado. Prueba de ello es que las víctimas son principalmente civiles palestinos, y que dentro de los 4.800 objetivos atacados por el Estado de Israel en esta última operación, fueron afectados de manera directa unas 10.600 viviendas, así como numerosos centros médicos, escuelas y pozos de agua (TeleSur, 2014d). Se continúa privilegiando los ataques contra la población civil como estrategia histórica de actuación del estado de Israel contra Palestina, si bien se ha recrudecido a partir de la operación "Plomo Fundido", cuyos hechos podrían ser procesados por la CPI tras la culminación de su actual examen preliminar. Entre otros, el informe de Amnistía Internacional (2009a) sobre la Operación Plomo Fundido, destacó:

Gran parte de la destrucción se llevó a cabo de manera gratuita y fue el resultado de ataques directos contra bienes civiles, así como de ataques indiscriminados, en los que no se distinguió entre objetivos militares legítimos y bienes civiles. Tales ataques violaron disposiciones fundamentales del derecho internacional humanitario, en especial la prohibición de los ataques directos contra civiles y bienes civiles (principio de distinción), la prohibición de los ataques indiscriminados o desproporcionados y la prohibición de los castigos colectivos (p. 1).

La existencia de estas víctimas implica la configuración de espacios que sintetizan el proceso de selección que realiza la criminalidad de Estado, y que muestran que esta criminalidad en la actualidad se configura de forma muy frecuente como criminalidad reconfiguradora:

a. Selección como dominación, identificable de diversas formas: ellos no son como nosotros (Said, 1996), o el prototipo moderno: "Hay amigos y enemigos. Y también extranjeros", donde este último constituye "un miembro de la familia de los innombrables", esto es, aquellos que no pueden ser incluidos dentro de la oposición (Bauman, 1996, p. 92 y 95). En palabras de Calveiro (2012): "cuanto más "totalizante" es una forma de dominación, menos tolerancia tiene para aceptar cualquier 
"afuera", de manera que convierte toda exclusión en eliminación lisa y llana” (p. 20).

b. Selección como determinación del binomio víctima/enemigo. De forma corriente, las víctimas de crímenes de Estado pertenecen a sectores populares, o a naciones no incluidas dentro de la hegemonía mundial, y por ello tienen una menor posibilidad de reclamar sus derechos ante los tribunales nacionales o extranjeras, en tanto que además, son concebidas como "enemigas" del Estado (Corte IDH, 2009a; Gallardo, 2009), o de la humanidad.

c. Selección y temor. Estos procesos se acompañan de acciones de angustia, temor e inseguridad, que acompañan las pretensiones de justificar la selección (Corte IDH, 2009a), que permite garantizar su conexión con la posibilidad de reorganización, lo que tiene y no tiene lugar, como señaló Bauman (1996) a través de argumentos de tipo endógeno o exógeno. El proceso de selección endógeno implica la recuperación de la noción del que no tiene lugar: “(...) El extranjero, quien no sólo está fuera de lugar, sino que, además, sin hogar, puede convertirse en un atractivo objeto de genocidio" (p. 109).

Los demás tiene conocimiento de la existencia de quienes tienen y no tienen lugar, exclusiones que se acompañan de ejercicios del control social mediante el terror. No en vano la exclusión social constituye a un tiempo objeto y fin de la persecución: "desprotegido jurídicamente en sus relaciones con los demás, el ser humano pasa a ser un objeto en la sociedad dentro de su Estado, sin que los ataques contra el mismo acarreen consecuencias jurídicas" (Alija Fernández, 2011, p. 394). Naomi Klein (2007) señala en términos elocuentes que las graves violaciones de derechos humanos constituyen una pretensión deliberada de aterrorizar a la población: "y se articularon activamente para preparar el terreno e introducir las 'reformas' radicales que habrían de traer ese ansiado libre mercado" (Klein, 2007, p. 31).

En la criminalidad de Estado de la actualidad se encuentran dos dimensiones principales del uso del terror, desarrolladas a nivel nacional como internacional mediante un etiquetamiento que incluso va de Estados a individuos ${ }^{2}$ : la relativa

2 Para detenerse sobre el etiquetamiento de Estados a individuos, se sugiere revisar: Chomsky (1998, 2005 y 2008) así como Álvarez Cobelas, 2007. a los lugares y a formas mismas de ejecución de acciones de terror, así como la que se refiere al tratamiento de sobrevivientes y víctimas en general que han sido objeto de selección. El caso de Palestina expresa una profunda elocuencia de ello, y de la utilización del Derecho como mecanismo de selección, como resalta Edward Said (1997):

No solo se nos ha pedido que aceptemos nuestra supresión como pueblo que tenía una vida real, como sociedad que existía de hecho en Palestina hasta 1948, y nuestro sometimiento a partir de ese año, sino que admitamos la complacencia y el aliento occidentales a nuestros opresores. Todo porque Occidente vio en Israel un prodigio de la democracia liberal, y la ocasión de indemnizar a las víctimas de las matanzas sufridas por los judíos, a pesar de que dichas matanzas fueran cometidas exclusivamente por europeos, y no por los palestinos, que han sido, a fin de cuentas, los que han tenido que pagarlas. A pesar de ello, y a pesar de las penalidades a las que nos ha sometido Israel, dimos un generoso paso al reconocer la existencia del Estado de Israel en las sesiones celebradas por el Consejo Nacional Palestino en Argelia en 1988. Este paso no ha encontrado equivalente todavía en la parte israelí. Todo lo que Israel hizo en Oslo fue reconocer a la OLP como representante del pueblo palestino, ignorando nuestra aspiración fundamental de alcanzar un grado de igualdad y reconciliación que permita el establecimiento de una auténtica paz.

En lugar de dar ese paso, Israel y EEUU se han obstinado en seguir presionando a la débil dirección palestina, hasta hacerla desmoronarse. (...) (p. 30).

En lo que corresponde a la segunda modalidad, se utilizan procedimientos de orden nacional, o la comisión de graves violaciones de DIDH. Sobre esta última, la utilización de la base militar de Guantánamo por Estados Unidos, ha buscado eludir la aplicación del DIDH (Abril, 2005).

Como otro criterio común en la construcción del concepto de enemigo del totalitarismo (Arendt y Calveiro) y del Estado (Gallardo, 2009; Zaffaroni, 2007a y 2012), se tiene la visión del Estado como instrumento de control. Ello confluye en 
la determinación de la noción de víctima de la criminalidad de Estado, con tres manifestaciones del concepto de enemigo para dicha criminalidad que han edificado una arquitectura compleja del concepto, aun cuando con un mismo resultado: la fusión de "las ideas de delincuente a castigar, enemigo a exterminar y Otro a desaparecer (...)" De esta forma se "orientó toda la maquinaria en torno a la persecución primero, la eliminación después y la desaparición por último" (Calveiro, 2012, p. 41).

(i) El enemigo bajo el signo del homo æconomicus o enemigo social. Se trata de un concepto general de las víctimas de la criminalidad de Estado, en tanto constituye uno de los reflejos de la razón instrumental en la modernidad.

Como se señaló, el homo æconomicus como homo penalis, fue observado desde Foucault como una constatación de la intervención (no exclusiva pero sí decisiva) de la economía en la configuración de la gubernamentalidad. Quien es señalado como enemigo de las lógicas del homo æconomicus, se vincula como criminal, como quien perturba la sociedad, un enemigo social (Foucault, 1996). En realidad la selección bajo el homo æconomicus, constituye una de las primeras nociones, y el concepto general de enemigo interno de la modernidad capitalista. Este concepto a su vez presenta dos implicaciones en la construcción de la criminalidad de Estado y sus víctimas. Por un lado, la determinación de particulares formas de victimización permite sostener los intereses del homo æconomicus, como se colige de la situación de Ciudad Juárez (Corte IDH, 2009; GunCuninghame, 2005; Segato, 2004; Staudt y Vera, 2006), configurándose como un lugar emblemático de realización de feminicidios, y de aplicación de la globalización económica y del neoliberalismo (Segato, 2004) con sus consecuentes efectos (Corte IDH, 2009). La correspondencia del homo æconomicus como criterio de definición del enemigo de Estado, con las restantes subcategorías que aquí se presentan, puede entenderse mejor con una reflexión sobre la situación de la criminalidad de Estado en Brasil, y en particular de los crímenes en relación con el aparato judicial y la acción policial:

La Constitución de 1988 garantiza los derechos humanos. Sin embargo, el sistema de justicia criminal (sistema penal) brasileño ha privilegiado la criminalización de pobres, negros y, particularmente, jóvenes. Cada año, un número significativo de individuos entra y sale del sistema de justicia criminal sin la debida red de protección social y sin el respectivo acceso a la justicia. En su mayoría son jóvenes expuestos a una enorme vulnerabilidad, con dificultades para acceder al mundo del trabajo. Su progresiva liberación (en régimen semiabierto, libertad asistida o condicional) muchas veces marca el reinicio de un proceso de estigmatización, victimización y criminalización terciaria. (Soares y Guindani, 2007, p. 66).

(ii)EI enemigo objetivo (Arendt, 1998; Calveiro, 2012; Gallardo, 2009), o enemigo absoluto (Horkheimer y Adorno, 1998) que representa un peligro para el sistema por su sola existencia. Es representado por Calveiro (2012) con sustento en Arendt, bajo un amplio matiz que va desde el enemigo objetivo por su nacimiento, o por su postura disidente.

El enemigo objetivo es marcado "por el mal absoluto como el mal absoluto" (Horkheimer y Adorno, 1998, p. 213), y puede tratarse de cualquier persona, como ha tenido lugar incluso de manera previa al inicio de la modernidad: las mujeres- brujas de la última edad media, la población judía durante una buena parte de su historia, el Islam y sus adeptos durante el Nuevo Humanismo Militar. Esta faceta presentada por Arendt (1998) y Calveiro (2012) como ejemplos de víctimas del terror del totalitarismo o de la esencia de la dominación totalitarista, caracteriza también espacios de criminalidad de Estado, esto es, que no llegan a la acentuación que exigiría un fenómeno totalitario.

El enemigo objetivo es un grupo poblacional escogido por el poder y edificado como víctima universal. Bajo este concepto, Löwy (2003) caracteriza la víctima de los crímenes de Estado cuando habla sobre el Proceso de Kafka: "Joseph $\mathrm{K}$., no tiene nacionalidad o religión determinada: la elección misma de una simple inicial en lugar del nombre del personaje refuerza su identidad universal; es el representante por excelencia de las víctimas de la máquina legal del Estado" (p. 102).

El proceso de aniquilamiento de las personas seleccionadas como enemigo objetivo o absoluto, no es el que se aplica a quien es considerado en 
general como enemigo social. El enemigo objetivo pasaría por un nuevo proceso de victimización, pues además son víctimas de deshumanización en cárceles o en campos de concentración (Bauman, 2011; Gallardo, 2009; Mate, 2003). Desde luego que el paso entre las dos categorías es cuando menos azaroso. Por ejemplo, el general colombiano Landazábal Reyes (1982) consideró dentro de la categoría de enemigo interno, a la población civil: "los indiferentes e indecisos forman parte de las filas del adversario, al que prestan apoyo por el sólo hecho de dejarlo prosperar" (p. 427). Dentro de esta misma tipología es posible ubicar la población judía en cuanto víctima cosmopolita del nazismo (Bauman, 2011).

El enemigo por su postura contrahegemónica. Puede considerarse una subcategoría dentro del enemigo objetivo. Incumbe al enemigo por su identidad política, el movimiento disidente, diverso del discurso oficial. En esta categoría han sido incluidos en el continente americano, los "intelectuales, artistas, estudiantes, docentes, líderes sindicales y otros múltiples actores que sufrieron las consecuencias de la violencia sistemática producida durante este periodo" (CIDH, 2011, párr. 501).

Justamente, se ha señalado que en la raíz del holocausto nazi está la pretensión hegemónica: "La existencia y el aspecto de los judíos comprometen la universalidad existente debido a su falta de adaptación" y en realidad la raza constituye: "la autoafirmación del individuo burgués"(Horkheimer y Adorno, 1998, p. 214). Esto es, se ha desarrollado "una peculiar articulación conceptual en la cual lo político y lo étnico cultural (...) en una imagen unitaria, que representaba una encarnación específica del enemigo de Occidente" (Feierstein, 2008, p. 24).

En múltiples casos adelantados en el sistema interamericano de protección de los derechos humanos, el análisis de contexto ha evidenciado acciones sistemáticas contra estudiantes y profesores de universidades públicas (Corte IDH, 2009a). Asimismo Calveiro (2012) resalta que en América Latina, el enemigo en la dimensión de identidad política fue etiquetado bajo el genérico subversivo. A partir de allí fue seleccionada y eliminada "toda una generación de dirigentes políticos, sociales, sindicales, militares nacionalistas, sacerdotes progresistas, intelectuales alternativos, descabezando, desarticulando, vaciando las sociedades para penetrarlas y controlarlas" (p 41).

Otro punto de conexión en los tres mecanismos expuestos, es la construcción social del enemigo. Como resalta Feierstein (2008) en relación con los procesos reorganizadores del nazismo y de la última dictadura en Argentina, se trata de una destrucción sistemática que busca ejercer impresiones a largo plazo en el grupo escogido: transformarlo "redefinir su modo de ser, sus relaciones sociales, su destino y su futuro" (p. 52). Es decir, se crea el enemigo para acabarlo y con ello, crear un sujeto a la medida del Estado.

Finalmente, se constata que la edificación del concepto de enemigo interno, se hace bajo una dosis de racismo como tecnología del poder. Foucault (2000) resalta el papel del racismo en la economía del Biopoder, a partir de la idea de la muerte de unos para alcanzar el fortalecimiento biológico propio de otro, como miembro de una raza o una población: "Podrán advertir que, en el fondo, aquí estamos muy lejos de un racismo que sea, simple y tradicionalmente, desprecio u odio recíprocos de las razas". (p. 234) De ahí que concluye que la especificidad del racismo moderno no subyace a ideologías o mentiras del poder, sino a "un mecanismo que permite el ejercicio del Biopoder. (...) al funcionamiento de un Estado obligado a servirse de la raza, de la eliminación de las razas y de la purificación de la raza, para ejercer su poder soberano" (p. 234).

El sostenimiento de los procesos de selección no niega su profundización. En la actualidad el proceso de inmunización de la racionalidad instrumental ha trocado el enemigo subversivo en el enemigo terrorista, donde como lo resalta Díaz Gómez (2012), el criterio de maldad se usará sobre "lo emergente, la novedad, en cuanto amenaza el orden del sistema social" (p. 173) y a partir del 11 de septiembre de 2011, se englobarán como terroristas. Pero la más lamentable de las profundizaciones del proceso de selección consiste en el tránsito al concepto de enemigo como no humano. A través de la tecnología se ha procedido a la creación en la hegemonía imperante de un Otro "como alguien exento de todo derecho" (Calveiro, 2012, 35), a través de una síntesis "tanto política como religiosa" (Feierstein, 2008, p. 64). Esta lectura ha tenido inicio en el proceso que Marx concebiría 
como el "carácter fetichista de la mercancía y su secreto" (Marx, 2008, p. 87 ss.), donde se presenta una desvinculación entre el sujeto y el objeto, mientras se invierte la relación, como advierte el filósofo Omar Prieto (2014): "pues se trasladan a las cosas, el valor en sí mismo de las personas" y de allí, al remitirse a las cosas el valor que reside en las personas, se llega a la deshumanización.

Entonces, resulta lógico afirmar que el sistema totalitario profundiza esta lectura, pues allí se pasa adicionalmente, de las pretensiones de desvertebramiento del sujeto colectivo, a la anulación del sujeto individual. De esta forma se crea una humanidad "carente de personalidad jurídica o política, reducida a la pura dimensión biológica e instrumental, una suerte de humanidad superflua"(Calveiro, 2012, p. 29). Esto ha sido evidenciado por la Corte Interamericana de Derechos Humanos, tanto en relación con el proceso de selección, como en la utilización de ciertas graves violaciones de derechos humanos, como la desaparición forzada, bajo dicha selección. En su voto razonado a la sentencia del caso Anzualdo Castro vs. Perú, sostuvo el juez Sergio García Ramírez: "La desaparición y otras expresiones del mismo linaje reaccionan sin arreglo al Derecho, de manera automática y brutal: no juzgan, suprimen"(Corte IDH, 2000a). La reducción a la dimensión instrumental en combinación con los procesos de selección de las víctimas, es campo de cultivo para la criminalidad de Estado:

Perseguidores y víctimas, en cuanto aquellos que ciegamente golpean y aquellos que ciegamente se defienden, pertenecen aún al mismo círculo fatal de desventura. El comportamiento antisemita se desencadena en situaciones en las que hombres cegados y privados de subjetividad son liberados como sujetos (Adorno y Horkheimer, 1998, p. 216).

Esta humanidad reducida a una dimensión instrumental que culmina en la deshumanización como mecanismo de comunicación internacional, no se presentó de manera global como rasgo previo a la Primera Guerra Mundial, pues a pesar de tratarse de una confrontación bélica internacional entre potencias hegemónicas, donde además tuvo lugar el genocidio armenio (Adorno, 1998) se sostuvo la idea de enemigo como igual. (Carmona Sánchez, 2013) Como resalta Calveiro (2003), una vez la persona ingresa en el proceso de aniquilamiento que se sintetiza en el campo de exterminio o la prisión, y se le utilizaba, entonces estaba: "lista para la fase final: la supresión de la vida biológica y la posterior "desaparición" del cuerpo mismo, del cadáver" (p. 119). En el caso colombiano se construyó también la difusa noción de enemigo interno no como enemigo, sino como no humano, y a partir de ella se tecnologizaron las ejecuciones extrajudiciales como reducción a la calidad de homo sacer. En la década de 1980, un comandante de inteligencia del Ejército Nacional, señaló:

La guerrilla es una apenas un apéndice de la subversión y tiene una importancia menor de la que generalmente se le atribuye; el peligro, en un proceso subversivo, lo constituye lo que los insurgentes han denominado la guerra política o sicológica. Este tipo de guerra está encaminada a tomar el control de los núcleos humanos; a fanatizar al pueblo con ideologías extremistas; a conformar organismos que se encarguen de manipular a las masas en favor de sus intereses; a desarrollar una acción que confunda a la nación, distorsione la verdad y cree la desconfianza; a infiltrar la administración (...)" (Zafra, 1987, p. 39).

Estas actuaciones han tenido una respuesta escasa del Derecho. Debe resaltarse el Auto A-164 de 2012, catalogado por la Comunidad de Paz de San José de Apartadó, como una de las pocas expresiones sensatas desde el Derecho, frente a la persecución que sufren y que titulan en cabeza del Estado. En dicho auto la Corte Constitucional generó una estrategia para construir mecanismos tendientes a crear condiciones para "la reconstrucción de la confianza" y la superación de "los obstáculos que han impedido asegurar de manera efectiva los derechos de los miembros de la Comunidad de Paz de San José de Apartadó y la no repetición de los hechos que generaron la vulneración de los mismos (...)” (CC, A-164 de 2012).

El proceso de Feierstein se corrobora con múltiples decisiones de la justicia nacional, que revelan los procesos de selección de víctimas del paramilitarismo en Colombia a partir de prácticas de etiquetamiento que confluyeron en una historia falsa "deliberadamente construida como una estrategia de impunidad jurídica y social" (J110IT, 25 de enero de 2013, p. 12. Ver asimismo: J110IT, 31 de enero de 2012; CSJ- SCP, 6 junio de 
2012). En la sentencia de primera instancia del proceso penal adelantado por el homicidio de los sindicalistas Valmore Locarno y Víctor Hugo Orcasita, se observó:

En cuanto a la intensidad del dolo habrá de indicarse que estamos ante una conducta que fue orquestada con antelación suficiente, preparada de manera detallada, llevando incluso a una campaña previa de desprestigio y de etiquetamiento de los dirigentes sindicales, haciéndolos pasar por guerrilleros con el fin de abonar el terreno para que tales decesos quedaran justificados por el objeto misional de las autodefensas (J110IT, 25 de enero de 2013. Ver asimismo: J 51PC, 15 de diciembre de 2011).

Decisiones judiciales como estas dejan ver diversos tipos de señalamientos vehiculando el proceso de etiquetamiento que en términos generales correspondían a: (i) la atribución de pertenencia o auxilio a la insurgencia sin fórmula de juicio (CSJ, SJyP; TSB, SJYP, 2013), (ii) la pertenencia a organizaciones o partidos políticos que no hacían parte de la hegemonía, como resalta el Tribunal Superior de Bogotá: "se manifestó por parte de HébertVeloza que una de las políticas de las autodefensas era "desarticular" y debilitar los movimientos que tenían una supuesta relación con la política de izquierda e influencia de las "guerrillas" de izquierda"(TSB, SJYP, 2013, párr. 194). (iii) la ubicación geográfica de las víctimas (TSB, SJYP, 2013). Asimismo, las decisiones judiciales en mención dejan ver que estos procesos de etiquetamiento confluyeron en crímenes generalizados (CSJ, SJyP), y además sistemáticos (J110IT, 25 de enero de 2013; CSJ- SCP, 6 junio de 2012; CSJ, SJyP,), que se desarrollaban bajo la pretensión de atemorizar a la población (TSB, SJYP, 2013):El Tribunal Superior de Bogotá, ha reseñado lo sostenido por el paramilitar Hébert Veloza:

(...) una de las formas de ganar la guerra era generar terror, una de las formas de combatir al enemigo era generar terror ante las comunidades, para que esas comunidades no le sirvan al enemigo, una forma de generar terror era esa: decapitando gente para generar terror ante la comunidad, por eso se presentaban estas situaciones (TSB, SJYP, 2013, párr. 188).
Por ello, llama la atención que el proceso descrito por Feierstein, coincida con algunas de las etapas de la configuración estatal a partir de la ilustración: Selección, discriminación, homogeneización y sacralización; a partir de lo cual se ha llegado a considerar que la diferencia y su reconocimiento es un asunto que genera incomodidad al Estado Ilustrado, y que la discriminación es un proceso propio de este Estado, luego entonces, de la modernidad. Se trata como destaca Fuentes Contreras (2013) de un proceso de discriminación estatal que se conecta con una propuesta de homogeneización "donde se construye un elemento incluyente de segunda mano o en su defecto de inclusión bajo el cumplimiento de los estándares impuestos por el modelo ilustrado" (p. 120).

\section{CONCLUSIONES}

La concepción de Genocidio como concepto sociológico, esto es, en tanto proceso fundacional o reorganizador, como la de crimen de Estado, entrañan procesos de selección de las víctimas/ enemigos. Se ha evidenciado así la existencia de tres tipos diferentes de subprocesos de selección: La selección como dominación, la selección como determinación del binomio víctima/enemigo, y la selección como ejercicio de temor que procura control social. Estos procesos a su vez generan tres categorías de víctimas de crímenes de Estado: el enemigo bajo el signo del homo æconomicus o enemigo social, el enemigo objetivo o absoluto, y como una subespecie de este último, el enemigo por su postura contrahegemónica.

También se advierte que no es suficiente asimilar simplemente genocidio a criminalidad de Estado para tener que este proceso de selección en realidad se lleva a cabo, aunque en efecto estas técnicas se consideran idénticas en lo que corresponde a una aproximación sociológica que busque explicar los orígenes de la criminalidad de Estado. En dicho orden, se ha corroborado que la criminalidad de Estado constituye un fenómeno de la modernidad que permanece hasta la actualidad con líneas acentuadas bajo el Nuevo Humanismo Militar. 


\section{BIBLIOGRAFÍA}

- ABRIL, R.(2005). De Guantánamo, a Bagdad. Estatuto Jurídico y trato a los "detenidos en la lucha contra el terrorismo". Revista electrónica de estudios internacionales, 9.[en línea].Disponible en http://www.reei. org/index.php/revista/num9/articulos/ guantanamo-bagdad-estatuto-juridicotrato-detenidos-lucha-contra-terrorismo. [Consultado octubre 27, 2012].

- Horkheimer, M. y Adorno, T. (1998). Dialéctica de la Ilustración. Fragmentos Filosóficos(3a Ed., J. J. Sánchez, Trad.). Valladolid: Editorial Trotta.

- ALBA RICO y GUANCHE J. C. (2012, diciembre 30). Entrevista a Santiago Alba por Julio César Guanche. [Archivo de video]. Disponible en : http://www.youtube.com/watch?v=U_ ek0X41H-Y. [Consultado julio 25, 2014].

- Alija Fernández, R. A.(2011). La persecución como crimen contra la humanidad. Barcelona: Publicaciones y ediciones de la Universidad de Barcelona.

- Althusser, L. (2005). Ideología y aparatos ideológicos del Estado. En La filosofía como arma de la revolución (25a ed., pp. 102-151.).México: Siglo XXI.

- AMNISTÍA INTERNACIONAL.(2009a). Israel/ Gaza. Operación "Plomo Fundido": 22 días de muerte y destrucción. [en línea]. Disponible en http://amnistiainternacional.org/ publicaciones/80-israel-gaza-operacionplomo-fundido-22-dias-de-muerte-ydestruccion.html. [Consultado agosto 26, 2014].

- ANDERSEN, M.L. (2006). Race, Gender, and Class Stereotypes: New Perspectives on Ideology and Inequality. Norteamérica, 1(1). [en línea]. Disponible en http://www. revistascisan.unam.mx/Norteamerica/pdfs/ n01/n0105.pdf. [Consultado octubre 10, 2012].

- ANDREASSI, A(2005). Dictadura militar en Argentina (1976-1983). Naturaleza y antecedentes del Estado genocida.[en línea].
Disponible en: http://www.espai-marx.net/ ca [Consultado octubre 2, 2012].

- Arendt, H.(1998). Los Orígenes del Totalitarismo. Madrid: Taurus.

- Bauman, Z.(2011). Modernidad y Holocausto, (6 ${ }^{\mathrm{a}}$ ed.). Madrid: Ediciones Sequitur.

- _ (1996). Modernidad y ambivalencia. En J Beriarin (Comp.). Las consecuencias perversas de la modernidad. Modernidad, contingencia y riesgo (C. S. Capdequí, Trad., pp. 73 -120). Barcelona: Anthropos.

- BAVARESCO, A. (2003). La crisis del estado-nación y la teoría de la soberanía en Hegel. Recerca. Revista de pensamiento y análisis, 3, 55-80. [en línea]. Disponible en http://www.raco.cat/index.php/ RecercaPensamentAnalisi / article/ view/106716/153085. [Consultado noviembre 15, 2010].

- BAYÓN, J. C. (2008). ¿Democracia más allá del Estado? En Estudios en homenaje al profesor Gregorio Peces-Barba, (Vol. IV, pp 71-92). Madrid: Dykinson.

- Benjamin, W. (1971). Para una crítica de la violencia. En Angelus Novus, (H. A. Murena, Trad., pp. 171-199). Barcelona: Edasa, Editorial Sur.

- Bordieu, P. y Wacquant, L. (2001). Las argucias de la razón imperialista (M. J. Furió Sancho, Trad.). Barcelona: Paidós.

- Calveiro Garrido, P. (2012). Violencias de Estado. La Guerra Antiterrorista y la Guerra contra el Crimen como Medios de Control Global. Buenos Aires: Siglo XXI Editores.

(2003). Memorias virósicas: Poder Concentracionario y desaparición de personas en Argentina. Acta poética, 24(2),111-134. [en línea]. Disponible en http://www.revistas.unam.mx/index. $\mathrm{php} / \mathrm{rap} /$ article/view/28360/26192. [Consultado octubre 10, 2010].

- CARMONA SÁNCHEZ, H. O. (2013). Consecuencias ontológicas en la asimilación del enemigo: de los Nacionalismos a la 
Hegemonía Política Contemporánea. En Lathouses. Violencia y Alteridad. 1, 23-30.

- CARVAJAL MARTÍNEZ, J. E. (2010). Derecho y cambio político en América Latina 19601980. Diálogos de saberes: investigaciones y ciencias sociales, 32, 259-272.

- COlOMBIA, CORTE CONSTITTUCIONAL. Auto 164 del 6 de julio de 2012. Magistrado Ponente: María Victoria Calle Correa.

CORTE SUPREMA DE JUSTICIA.

Sala de Casación Penal. Sentencia del 21 de septiembre de 2014. Magistrado Ponente. Sigilfredo Espinoza Pérez. Segunda instancia de Justicia y Paz, Proceso No. 32022.

JUZGADO ONCE PENAL DEL CIRCUITO ESPECIALIZADO DE BOGOTÁ .Proyecto OIT. Sentencia del 25 de enero de 2013. Procesado Jaime Blanco Maya. Víctimas: Valmore Locarno Rodríguez y Víctor Hugo Orcasita Amaya. Radicado: 110013107011-2011-00026-00.

- JUZGADO ONCE PENAL DEL CIRCUITO ESPECIALIZADO DE BOGOTÁProyecto OIT. Sentencia del 31 de enero de 2012. Procesados: Ramiro Rengifo y Roberto Vargas Gutiérrez.. Víctima: Jesús Orlando Crespo Cárdenas. Radicado: 110013107011-2011-00024.

- _ TRIBUNAL SUPERIOR DEL DISTRITO JUDICIAL DE BOGOTÁ.Sentencia de 30 de octubre de 2013. Magistrado Ponente: Eduardo Castellanos Roso. Proceso Segunda instancia de Justicia y Paz. No. 11-001-60-00 253-2006 810099. Rad. interno 1432.

- COMISIÓN INTERAMERICANA DE DERECHOS HUMANOS.(2011). Caso No. 12.590.José Miguel Gudiel Álvarez y otros ("Diario Militar"), Guatemala. Demanda presentada por la CIDH el 18 de febrero de 2011.

$\bullet$ (2001). Caso No. 11.625.

María Eugenia Morales de Sierra (Guatemala). Informe de Fondo, No. 4/01. 19 de enero de 2001.

2013). Orientación sexual, identidad de género y expresión de género: algunos términos y estándares relevantes. [en línea]. Disponible en http://www. oas.org/es/cidh/lgtbi/docs / CIDH.\%20 Estudio \% 20 s obre \% 200 S, \% 20 I G \% 20 y\%20EG.\%20T\%C3\% A9rminos\%20y\%20 est $\%$ C3\%A1ndares.doc.[Consultado abril 17, 2014].

- CORREAS, O. (2006). Los derechos humanos. Entre la historia y el mito. Revista Crítica Jurídica, 25, 269-292.

- _ (1988). Teoría Sociológica del Derecho y Sociología Jurídica. En Crítica Jurídica, 7. Puebla: Universidad Autónoma de Puebla.

- CORTE INTERAMERICANA DE DERECHOS HUMANOS. (2009).Caso Anzualdo Castro vs. Perú. Excepción Preliminar, Fondo Reparaciones y Costas. Sentencia de 22 de septiembre de 2009. Serie C No. 202

- (2009).Caso González y otras ('Campo Algodonero') vs. México. Excepción Preliminar, Fondo, Reparaciones y Costas, Sentencia de 16 de noviembre de 2009, Serie C No. 205.

$\bullet$

(2006). Voto razonado de A.A. Cançado Trindade a la Sentencia de la Corte Interamericana de Derechos Humanos, Caso Goiburú et al. vs. Paraguay, Fondo, Reparaciones y Costas, Sentencia de 22 de septiembre de 2006, Serie C No. 153.

- DÍAZ GÓMEZ, Á. (2012). Hacer morir y dejar vivir... Hacer vivir y dejar morir: el caso de "los falsos positivos". En: Castor M.M. B. Ruiz y R. A. Duarte Cuadros, La urbe global y el gobierno de la vida humana: Justicia, alteridad y memoria en los espacios de poder. (1aㅡ. Ed). Bogotá: Universidad Libre. Facultad de Filosofía.

- DUSSEL, E. (2000). Europa, modernidad y eurocentrismo. En Eduardo Lander (Comp.), La colonialidad del saber: Eurocentrismo y Ciencias Sociales. Perspectivas latinoamericanas (pp. 24-33). Buenos Aires: Consejo Latinoamericano de Ciencias Sociales. (Clacso). 
- Feierstein, D. (2008). El Genocidio como práctica social. Entre el nazismo y la experiencia argentina. Buenos Aires: Fondo de Cultura Económica.

- Fioravanti, M. (1996). Los Derechos Fundamentales. Apuntes de Historia de las Constituciones, (M. Martínez, Trad.). Madrid: Trotta.

- Foucault, M. (2000). Defender la sociedad. Curso en el College de France (1975-1976). (1 1 Ed. en español, H. Pons, Trad.) (Buenos Aires: Fondo de Cultura Económica. [Ver, genealogía del racismo]

- (1996a). Genealogía del racismo. (T. A. Tzveibe, Trad.). La Plata: Editorial Altamira. [Ver, Defender la Sociedad]

- _ (1998). Historia de la Sexualidad 1. La Voluntad de saber. (25a ed. en español) México: Siglo XXI Editores.

- _ (1996). La verdad y las formas jurídicas. (E. Lynch, Trad.) Barcelona: Gedisa.

- (2007). Nacimiento de la biopolítica. Curso en el College de France (1978-1979). (1 $1^{\text {a }}$ Ed. en español) Buenos Aires: Fondo de Cultura Económica.

- _ (1990). Tecnologías del yo y otros textos afines. (, 1므 Ed, M. A. Salazar, Trad.). Barcelona: Paidós Ibérica: I.C.E. de la Universidad Autónoma de Barcelona.

- _ (2012b). Vigilar y Castigar. Nacimiento de la Prisión. (2 $2^{\underline{a}}$ Ed., $3^{\underline{a}}$ Reimpresión) Buenos Aires: Siglo XXI Editores.

- Fuentes Contreras, E. H. (2013). El ocaso del Estado moderno. Bogotá: Universidad de Bogotá Jorge Tadeo Lozano.

- Gallardo, H. (2009). Derechos Humanos como Movimiento Social, (2ª Reimpresión) Bogotá: Ediciones Desde Abajo.

- Garzón Valdés, E. (2001). Filosofía, política, derecho. Valencia: Universidad de Valencia.

- Girard, R. (1986). El chivo expiatorio. Barcelona: Anagrama.

- Gramsci, A. (1980). Notas sobre Maquiavelo, sobre la política y sobre el Estado moderno
( J. Aricó, Trad.), Buenos Aires- Madrid: Ediciones Nueva Visión.

- (2005a). Tres principios, tres órdenes; en Antología, Selección, traducción y notas de Manuel Sacristán ( $5^{a}$ Ed.). México: Siglo XXI.

- Gun Cuninghame, P. (Septiembre de 2005). Globalización, maquiladoras e identidades transnacionales en Ciudad Juárez. Ponencia para el XXVIII Encuentro Red Nacional Investigadores Urbanos: Dilemas de la sociedad fronteriza. Encuentro llevado a cabo en la Ciudad Juárez, Chihuahua. [en línea]. Disponible en http://www2.uacj. $\mathrm{mx} / \mathrm{ICSA} /$ Investiga/RNIU/pnencias\%20pdf/ Ponencia\%20Patrick\%20C..pdf. [Consultado junio 12, 2014].

- Hegel, G, W. F. (2000). Rasgos fundamentales de la filosofía del Derecho o compendio de derecho natural y ciencia del Estado. ( E. Vásquez, Trad.). Madrid: Biblioteca Nueva.

- Hobbes, T. (2005). Leviatán. O la material, forma y poder de una república eclesiástica y civil. (2 ${ }^{\mathrm{a}}$. Ed. en español). México: Fondo de Cultura Económica.

- Hobsbawm, E. (1998) Historia del Siglo XX (3Reimp.). Buenos Aires: Crítica.

- Horkheimer, M.y Adorno, T. (1998). Dialéctica de la Ilustración. Fragmentos Filosóficos (3a Ed, J. J, Sánchez, Trad.). Valladolid: Editorial Trotta.

- Ihering, R Von.(2006). El Fin en el Derecho, Bogotá: Axel Editores.

- Inazumi, M. (2005). Universal Jurisdiction in Modern International Law: Expansion of National Jurisdiction for Prosecuting Serious Crimes under International Law, 19, Antwerpen: Intersentia.

- INTERNATIONAL COURT OF JUSTICE. (1951). Advisory Reservations to the Convention on the Prevention and Punishment of the Crime of Genocide, 28 May 1951, LEG 16/05 (6). [en línea]. Disponible en http://www.icj-cij.org/docket/ index.php?p1 $=3 \& \mathrm{p} 2=2 \&$ case $=12 \& \mathrm{p} 3=0$. [Consultado mayo 4, 2012]. 
- Kant, I. (2008). La Metafísica de las Costumbres, Estudio Preliminar de Adela Cortina Orts, Traducción y notas de Adela Cortina Orts y Jesús Connil Sancho (4a Edición). Madrid: Edit. Tecnos.

- KAUZLARICH, D., MULLINS, C. W. \& MATTHEWS, R. A. (2003). A Complicity Continuum of State Crime, Contemporary Justice Review, 6(3), 241-254.

- Klein, N. (2007). La doctrina del Shock. El auge del capitalismo del desastre. Barcelona: Paidós.

- Landazábal Reyes, F. (1982). Conflicto social. Medellín: Editorial Bedout.

- LÖWY, M., (2003). De Mendel Beiliss, el judío paria, a Joseph K., la víctima universal. Una interpretación de El proceso de Kafka (E. Cohen y M. Balcázar, Trad.). [en línea]. Disponible en: http://www.revistas.unam. $\mathrm{mx} / \mathrm{index} . \mathrm{php} / \mathrm{rap} /$ article/view/28359. [Consultado octubre 10, 2012].

- Marx, K. El Capital. Crítica de la Economía Política. Libro Primero. El proceso de producción de capital ( $1^{\mathrm{a}}$ Ed. en español, $28^{\mathrm{a}}$ reimp, P. Scaron, Trad.). México: Siglo XXI Editores.

- Mate, R. (2003). Por los campos de exterminio. ( $1^{\mathrm{a}}$ ed.). Barcelona: Anthropos.

- MONTES BERGES, B. (2008). Discriminación, prejuicio, estereotipos: conceptos fundamentales, historia de su estudio y el sexismo como nueva forma de prejuicio. Revista electrónica Universidad de Jaen. 3(1).

- UN, GENERAL ASSEMBLY. (1948). Prevention and Punishment of the Crime of Genocide. Resolution 260 A (III), de 9 de diciembre de 1948. A/RES/3/260. [en línea]. Disponible en http://www.un-documents.net/a3r260. htm. [Consultado mayo 6, 2012].

- ONU, CONSEJO DE DERECHOS HUMANOS. (2009). Situación de los derechos humanos en Palestina y otros territorios Árabes ocupados. Informe de la Misión de Investigación de las Naciones Unidas sobre el conflicto en Gaza. A/HRC/12/48.[en línea].
Disponible en http://daccess-dds- ny.un. org/doc/UNDOC/GEN/G09/158/69/PDF/ G0915869.pdf?OpenElement. [Consultado agosto 22, 2012].

- _ (1985) Revised and updated report on the question of the prevention and punishment of the crime of genocide, prepared by Mr. B. Whitaker. E/CN.4/ Sub.2/1985/6.

- _ (1972, May 23) Study of the question of the prevention and punishment of the crime of genocide. Preliminary report by Mr. Nicodeme Ruhashayankiko, Special Rapporteur. Distr. Limited. E/ CN.4/Sub.2/L.565. [en línea]. Disponible en http://daccess-dds-ny.un.org/doc/ UNDOC/LTD/N72/110/60/PDF/N7211060. pdf?OpenElement. [Consultado noviembre 4 , 2012].

- PERÚ, CORTE SUPREMA DE LA REPÚBLICA, SALA PENAL ESPECIAL, Sentencia del 7 de abril de 2009, Expediente $N^{\circ}$ AV 19-2001 (acumulado), Casos Barrios Altos, La Cantuta y sótanos SIE, Sentencia Condenatoria contra Alberto Fujimori. [en línea]. Disponible en http://www.deigualaigual.net/es/derechoshumanos / 52 -derecho/3443-textosentencia-fujimori-culpable. [Consultado junio 5, 2012].

- _ FISCALÍA SUPREMA EN LO PENAL. Opinión Fiscal sobre recurso de Nulidad. 31 de agosto de 2009. Expediente $\mathrm{N}^{\circ} \mathrm{AV} 19-2001$ (acumulado), Casos Barrios Altos, La Cantuta y sótanos SIE contra Alberto Fujimori. [en línea] Disponible en http://www.mpfn.gob. pe/descargas/informes/01092009112731_ VER_DICTAM E N_COMPLET O.pdf. [Consultado junio 15, 2013].

- PRIETO, O. (3 de septiembre de 2014).“El fetichismo de la mercancía: Daños colaterales". VI ciclo de conferencias de filosofía: Lecturas contemporáneas del pensamiento marxista. Conferencia llevada a cabo por el Programa de Filosofía. Área de Procesos de Pensamiento. Facultad de 
Ciencias Humanas, Universidad Autónoma de Colombia, Bogotá, Colombia.

- QUIJANO, A. (1999). iQué tal raza!. En Familia y Cambio social. Lima: Cecosam.

- RAJAGOPAL, B. (2003). Academic freedom as a human right: An internationalist perspective. Academe, Journal of the American Association of University Professors. (May-June), 25-28.

- Rivera Beiras, I. (2004a) Forma-Estado, mercado de trabajo y sistema penal ("Nuevas" racionalidades punitivas y posibles escenarios penales). En R. Beiras (Coord.), Mitologías y discursos sobre el castigo. Historia del presente y posibles escenarios (pp. 287 -326) Barcelona: Observatorio del Sistema Penal y los Derechos Humanos de la Universidad de Barcelona, Anthropos.

- Roberts, J.M. (2010). Historia del Mundo. De la Prehistoria a nuestros días, Barcelona: Random House Mondadori.

- Rousseau, J. J. (1989). El Contrato Social o Principios del Derecho Político. Medellín: Edilux Ediciones- Susaeta Ediciones.

- Said, E. (1996) Cultura e imperialismo. (N. Catelli, Trad.). Barcelona: Editorial Anagrama.

- Sandoval Huertas, E. (1979). La violencia de contenido criminológico penal. Tesis de maestría. Bogotá: Universidad Externado de Colombia.

- SANTOS, B. DE S. (2005). Beyond neoliberal governance: The world social forum as subaltern Cosmopolitan politics and legality. En B. de Sousa Santos and C. Rodríguez Garavito (Eds.), Law and Globalization from Below (29-63). New York: Cambridge Studies in Law and Society.

- SEGATO, R. L. (2004) Territorio, soberanía y crímenes de segundo Estado: la escritura en el cuerpo de las mujeres asesinadas en Ciudad Juárez (362).Brasilia: Universidade de Brasilia.

- Smith, A. (1794). Investigación de la naturaleza y causas de la riqueza de las naciones (J. Alonso Ortiz, Trad.). [en línea]. Valladolid: En la oficina de la viuda é hijos de Santander. Disponible en: http://stolpkin. net/IMG. [Consultado julio 12, 2014].

- SOARES, L. E. Y GUINDANI, M. (2007). La tragedia brasileña: la violencia estatal y social y las políticas de seguridad necesarias. En: Nueva sociedad, 208, pp.56-72.

- STAUDT, K. Y VERA, B. (2006). Mujeres, políticas públicas y política: los caminos globales de Ciudad Juárez, Chihuahua- El Paso, Texas. En: Región y sociedad. 18(37).

- Tugendhat, E. (1998). Gitanos y judíos. En Ernest Tugendhat, Conferencias y compromisos 1978-1991. (Elisa Lucena. trad.). Madrid: Tecnos.

- _ (1992) Justicia y Derechos Humanos. Barcelona: Universidad de Barcelona.

- Villoro, L. (1992). El Pensamiento moderno. Filosofía del Renacimiento (1a. Ed.). México: Fondo de Cultura Económica.

- Zaffaroni, E. R., (2012). Crímenes de Masa (2a Ed. Ampliada). Buenos Aires: Ediciones Madres Plaza de Mayo.

- _ (2007a). El Crimen de Estado como Objeto de la Criminología. En: Contribuciones Críticas al Sistema Penal de la Post Modernidad, In Memoriam a Eduardo Novoa Monreal. Santiago de Chile: Universidad Central de Chile, Facultad de Ciencias Jurídicas y Sociales.

- _ (2011). El enemigo en el derecho penal ( $2^{\mathrm{a}}$ Ed.). México DF: Ediciones Coyoacán.

- _ (1993). Hacia un realismo jurídico penal marginal (1를. Ed.). Caracas: Monte Ávila Editores Latinoamericana.

- ZAFRA GALVIS, O. (1987) Conceptos sobre inteligencia en la guerra subversiva, Revista Fuerzas Armadas, 42 (122).

- ŽIŽEK, S. (2002) The Matrix: Or, The Two Sides of Perversion. En: William Irwin (edt.) The Matrix and Philosophy. Welcome to the desert of the real. (240-266) Chicago: Open Court. 
(2006) Órganos sin Cuerpo. Sobre Deleuze y consecuencias (1 $1^{\underline{a}}$ ed.) Valencia: Pre-Textos.

- (2008). Arte e ideología en Hollywood. Una defensa del platonismo. (C. Rendueles, Trad.). En: Žižek, S.; Alemán, J. y Rendueles, C. Arte, ideología y capitalismo (10-49). Madrid: Consorcio del Círculo de Bellas Artes.

- __. (2011) En contra de los Derechos Humanos, Revista Suma de Negocios, 2(2), 115-127.

\section{NOTAS DE PRENSA Y NOTICIAS EN INTERNET}

Cronología de los ataques de Israel contra la Franja de Gaza. (2014, Julio 22). Abc Internacional. [en línea]. Disponible en: http://www.abc.es/ internacional/20140710/abci-cronologiais rael-gaza-201407100908.html, [Consultado agosto 26, 2014].

Israel mató a 91 palestinos en la última semana. (2014, Agosto 24) TeleSur noticias. [en línea] Disponible en: http://www. telesurtv.net/news/91-muertos-en-Gazadesde-el-lunes-20140824-0017.html. [Consultado agosto 26, 2014].

La ONU cifra en 280.000 los refugiados en la Franja de Gaza (2014, Agosto 22). Palestinalibre.org. [en línea]. Disponible en http://www.palestinalibre.org/articulo. php?a=52088. [Consultado agosto 22, 2014].

Los números rojos del conflicto de Hamas e Israel en Gaza. (2014, Julio 26). Abc Internacional. [en línea]. Disponible en: http://www.bbc.co.uk/mundo/ noticias/2014/07/140726_gaza_conflicto_ israel_numeros_yv.shtml. [Consultado agosto 22, 2014].
Nuevo ataque israelí deja 10 muertos en Palestina. (2014, agosto 25) TeleSur noticias. [en línea]. Disponible en http:/ / www.telesurtv.net/news / Nuevo-ataque-israeli-deja-10-muertosen-Palestina--20140825-0059.html [Consultado agosto 26, 2014].

Operación Pilar Defensivo 2012: Cronología de la ofensiva de Israel sobre Gaza (FOTOS) (2012, Noviembre 20) The Huffington Post.. [en línea]. Disponible en :http:// www.huffington post.es/2012/11/20/ cronologia-de-los-ataques_n_2166069. html. [Consultado agosto 26, 2014].

'Pilar Defensivo' (2012, Noviembre 21). Palestinalibre.org. [en línea]. Disponible en http://www.palestinalibre.org/articulo. php?a=42167. [Consultado agosto 26, 2014].

Alerta ONU que Palestinos de Gaza están "al borde del precipicio". (2014, Julio 31). Noticias RT. [en línea]. Disponible en http://actualidad.rt.com/actualidad/ view/133768-onu-victimas-ataques-israelgaza-civiles. [Consultado agosto 2, 2014] WikiLeaks: Guerra contra Gaza fue planificada años atrás. (2014, Agosto 25). TeleSur noticias. [en línea] Disponible en http://www.telesurtv.net/news/ Masacre-a-Gaza-fue-planificada-haceaos--20140825-0025.html. [Consultado agosto 25, 2014].

Destrucción en Gaza (2014, agosto 5) TeleSur noticias. [en línea]. Disponible en: http://www.telesurtv.net/telesuragenda/ Destruccion-en-Gaza-20140805-0017. html. [Consultado agosto 26, 2014].

UMAÑA HERNÁNDEZ, C. (2013,Abril 13). Gracias por no doblegarte, papá. [en línea]. Disponible en: http://www.elespectador. com/noticias/nacional/articulo-415924gracias-no-doblegarte-papa [Consultado abril14, 2013]. 
